[rVV-r

\author{
أهمية استخدام نظام الترميز السلعي

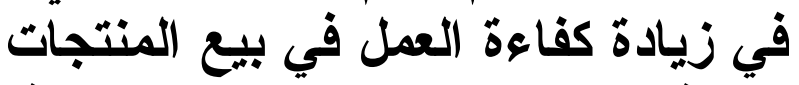

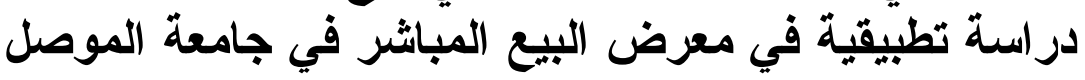 \\ منذر خضر المهتدي \\ مدرس مساعد - قسم إدارة الأعمال \\ كلية الإدارة والاقتصاد - جامعة الموصل \\ muntheralmuhtady@yahoo.com
}

\begin{abstract}
المستخلص

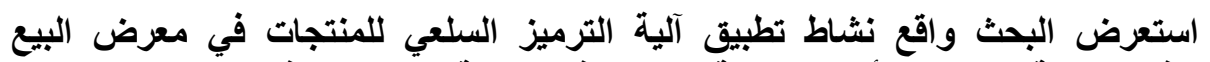

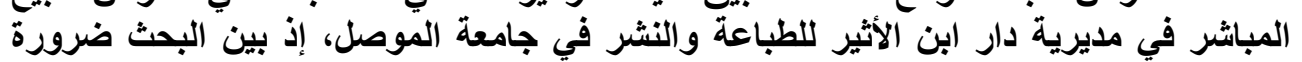

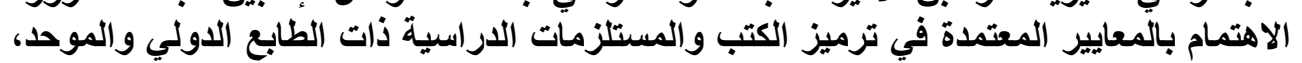

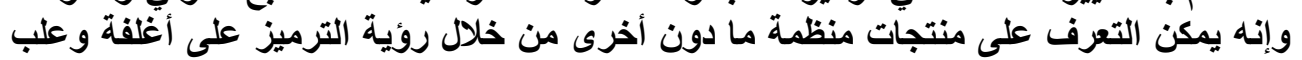

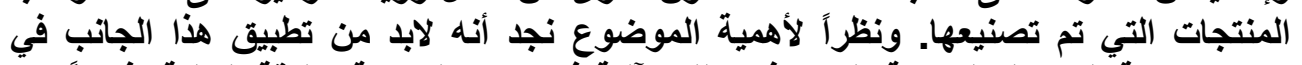

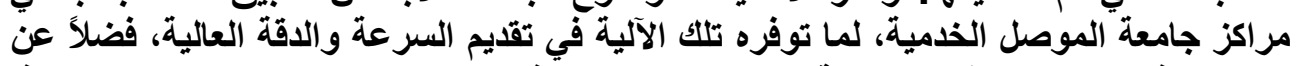

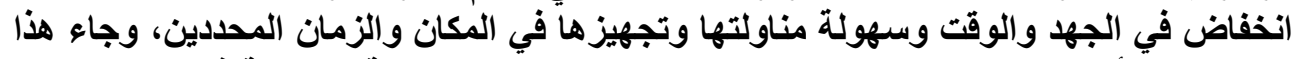

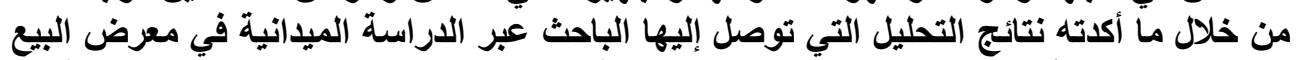

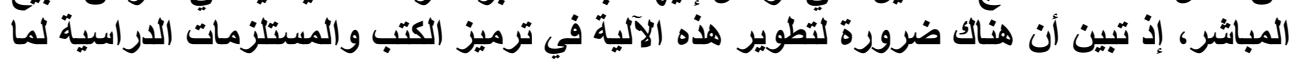

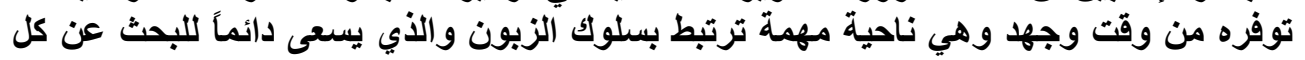
ما هو متميز.
\end{abstract}




\title{
The Importance of Using the Barcode Mechanism in Increasing Proficiency Work in Selling Products" An Application Study in the Direct Sale Show in Mosul City university'
}

\author{
Munther Kh. Al-Muhtady \\ Assistant Lecturer \\ Department of Business Administration \\ University of Mosul
}

\begin{abstract}
The research shows the situation of applying the mechanism of product barcode in IbnAltheer direct sale exhibition center in the University of Mosul. It shows the equal necessity of applying and taking care of the internationally applied standards in assigning the books and stationary equipments barcode. Therefore, it is possible to recognize the products of each organization through the barcode on stuffs and boxes of the products. This topic is so important that it should be applied on other University Service Centers. It will have its effect on the speed and high accuracy of doing the work. It will as well save effort and time in delivering and supplying on specific time and place. This was approved by the researcher through fields study in the direct sale show. Research showed the necessity of developing this mechanism in bar-coding the books and stationary equipments due to time and effort saving. This is an important aspect related to customer behavior who always seeks all that prominent.
\end{abstract}

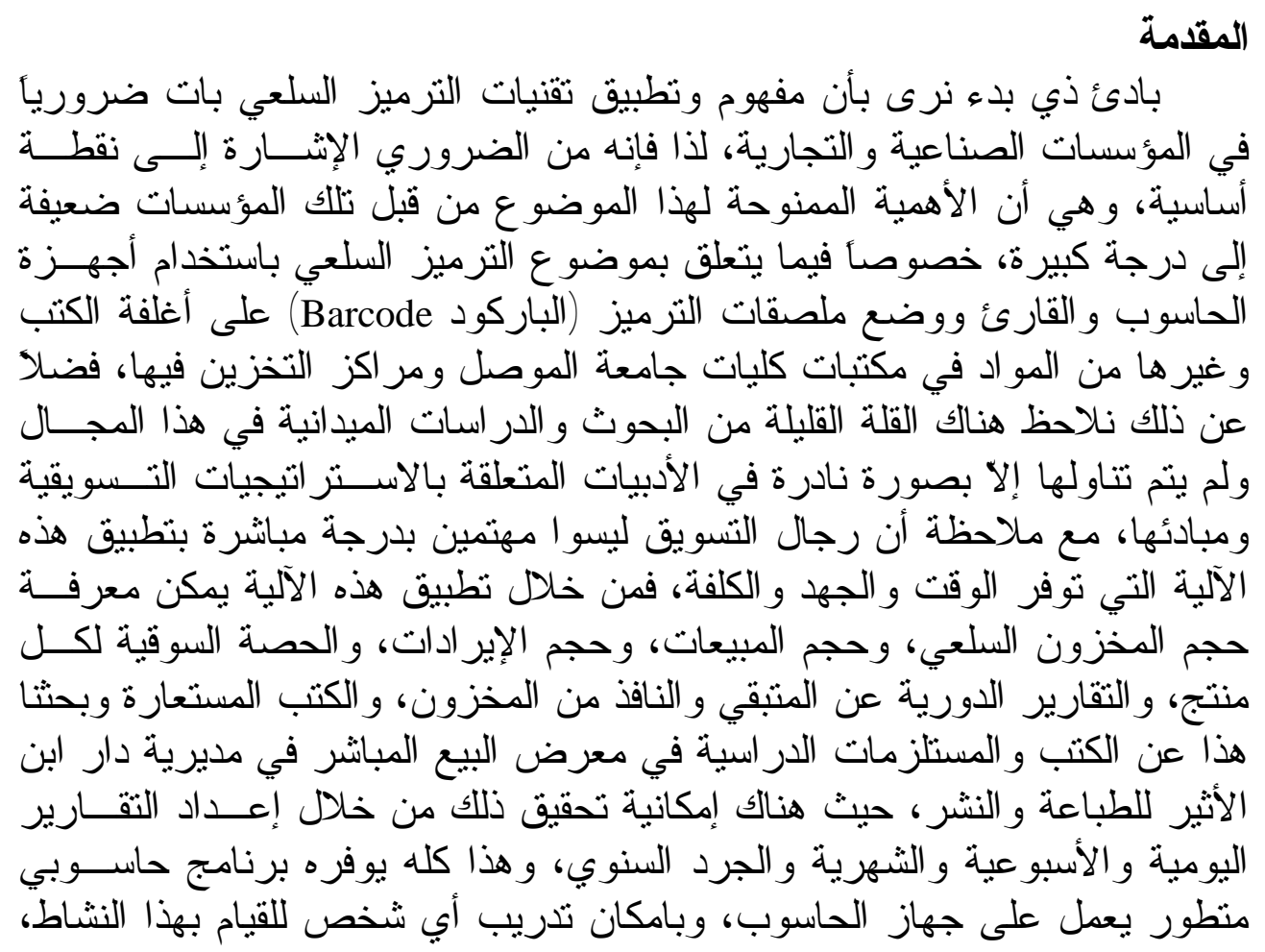




\section{المهتدي [ [}

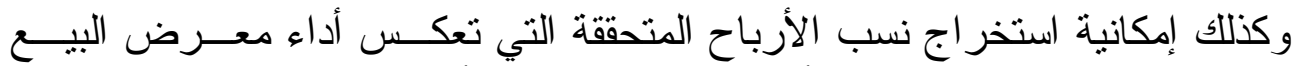

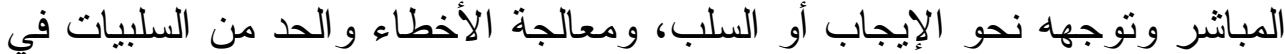

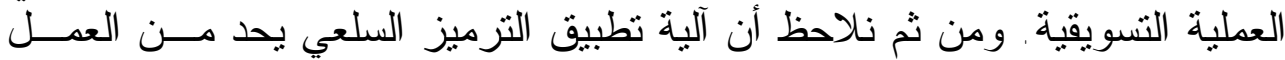

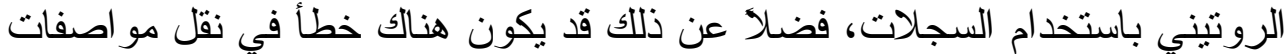

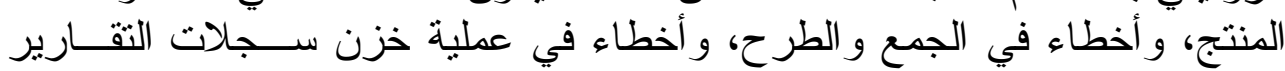

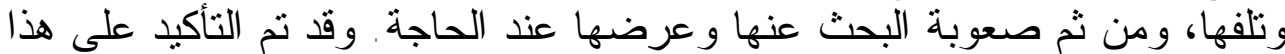

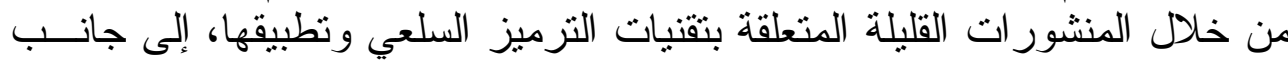

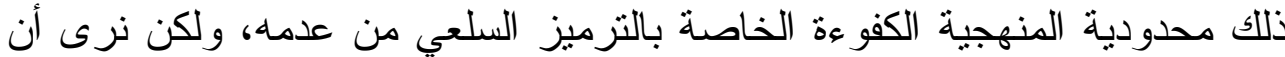

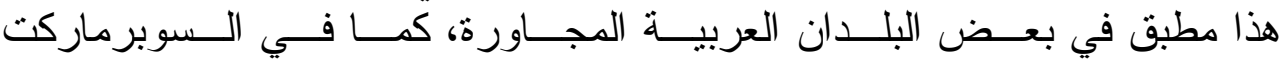
Supermarket

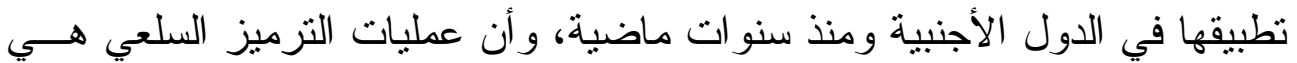

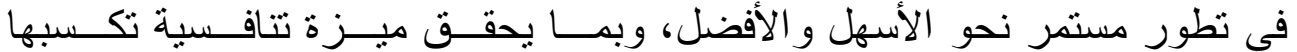
المؤسسات في تقدمها الإنتاجي و الخدمي.

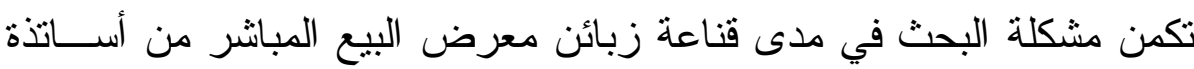

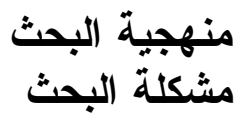

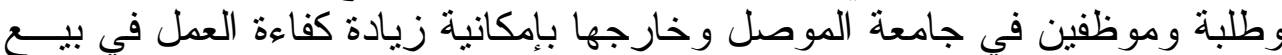

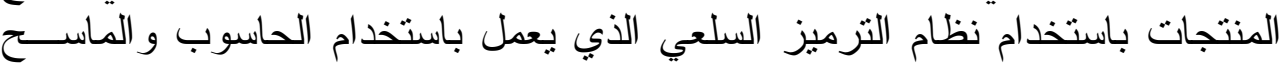

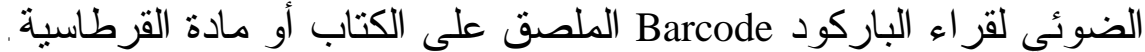

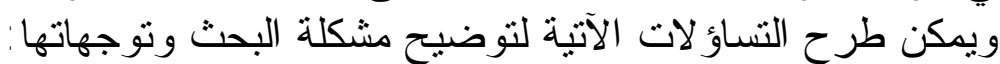

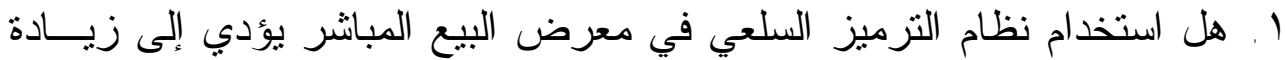
كفاءة العمل في بيع المنتجات؟

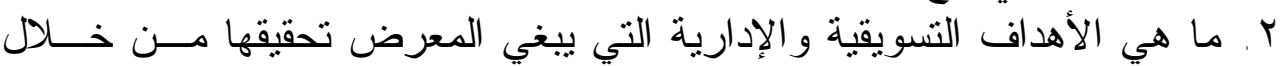
استخذام نظام الترميز السلعي لمنتجاته؟

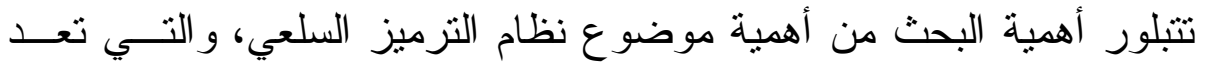

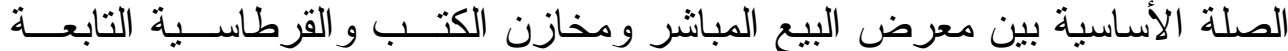

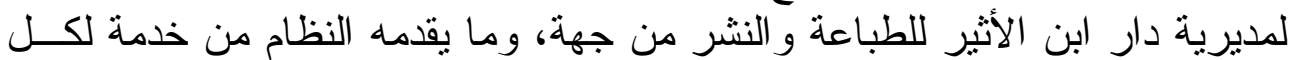

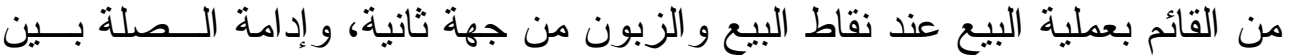

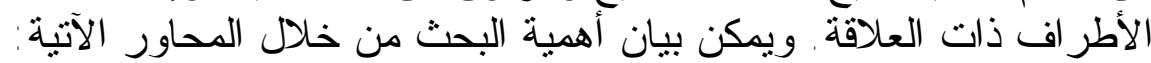

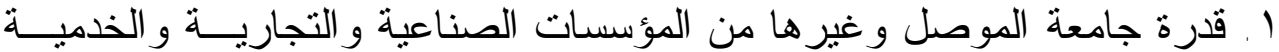

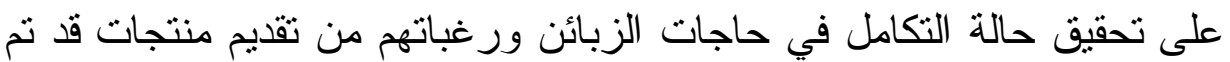
ترميز ها، و هذا يساعد جميع الأطر اف (المنتج و المؤسسة وتاجة فئر الجملة وتاجر 


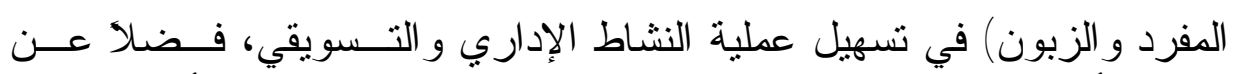

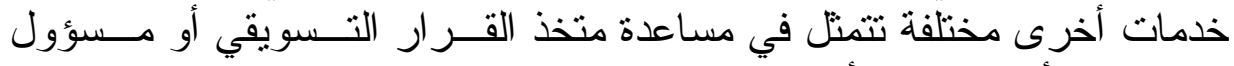

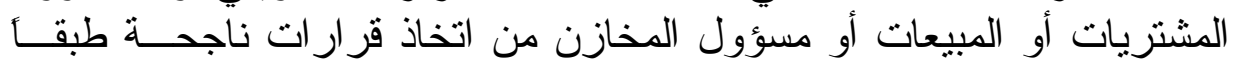

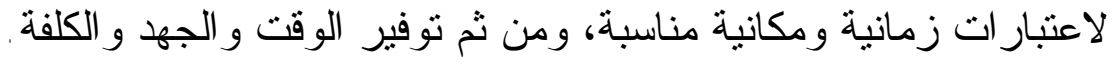

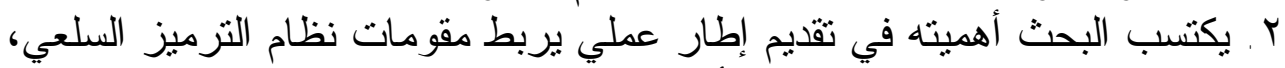

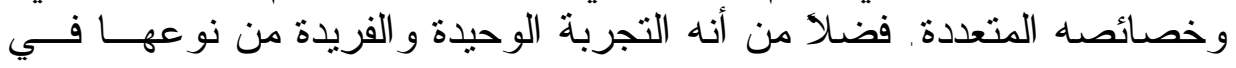

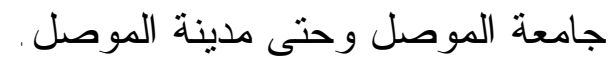

\section{هاف البحث}

يهدف البحث إلى عرض آلية جديدة تجمع بين ما قدمــهـ الكنهـاب فــي إدارة

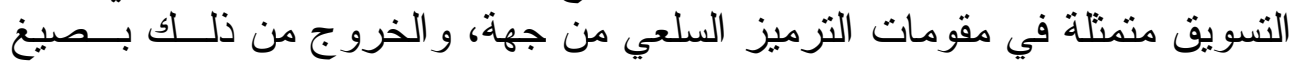

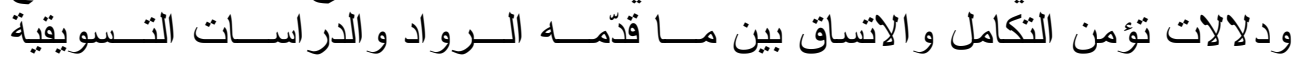

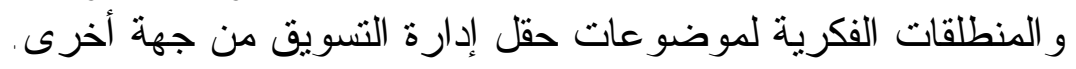

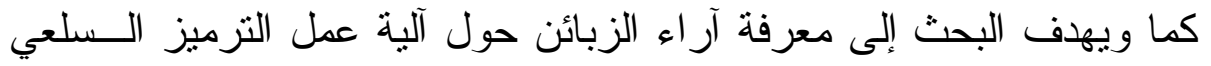

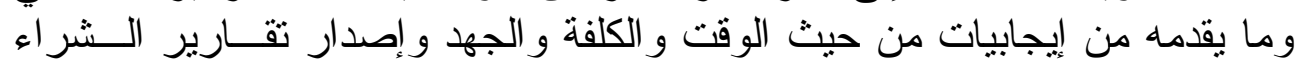

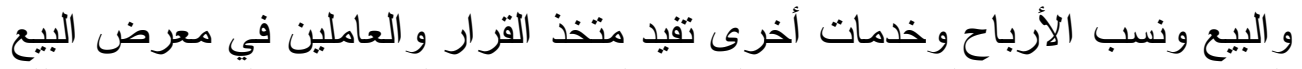

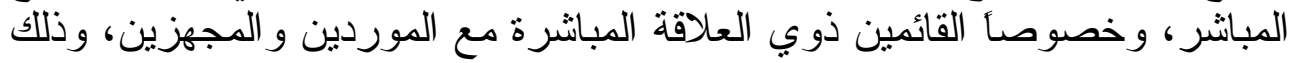

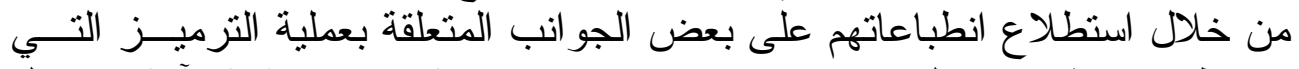

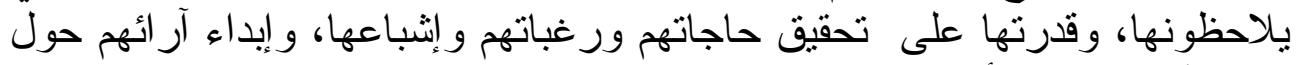

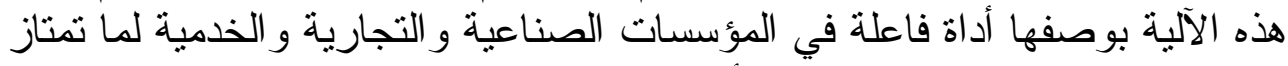
من خصائص إيجابية تخدم جميع الأطر اف ذوري العناف العالقة.

$$
\text { فرضيات البحث الفرضية الآتية و التي تخص موضوع البحث: }
$$

- تقترن زيادة كفاءة العمل في بيع المنتجات بلفئ موضتخدام الرمز السلعي (Barcode).

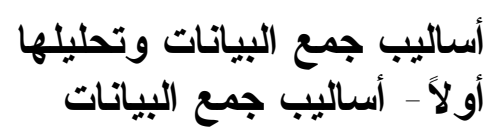

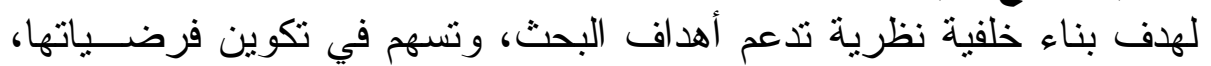

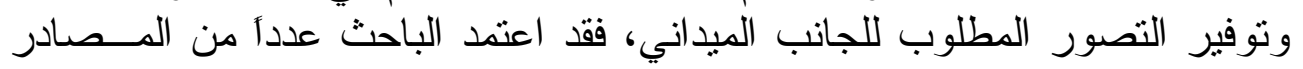

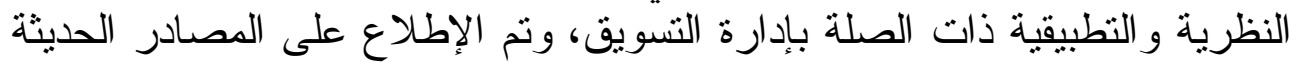

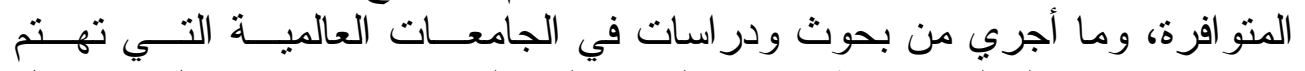

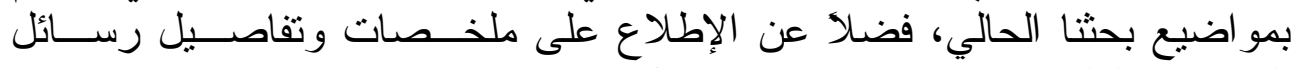
الدراسات العليا، كما تمت الاستفادة وبشكل كبير من استخدام شبكة الإنترنت. 


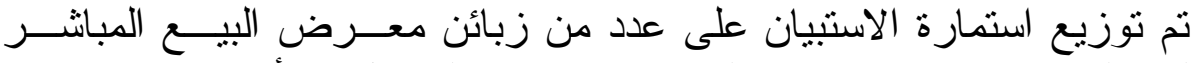
ثانياً - أساليب التحليل الإحصائي

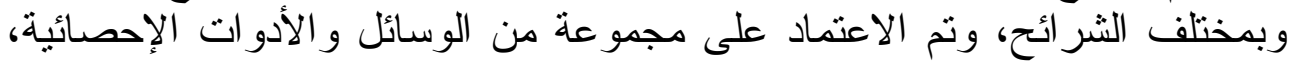

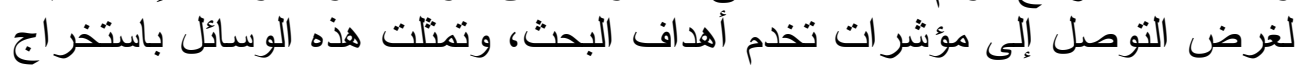

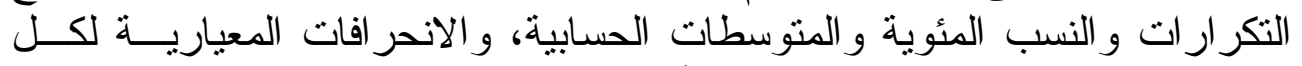

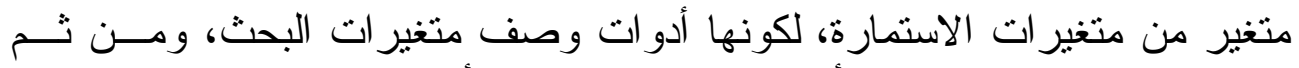

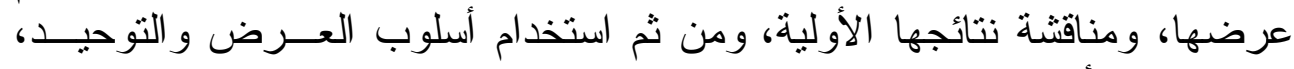
و وستخر اج الأهمية النسبية لكل متغير من متغير ات التهن البحث.

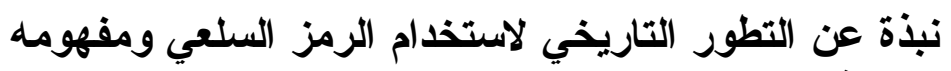

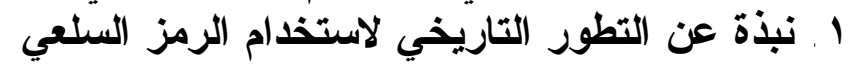

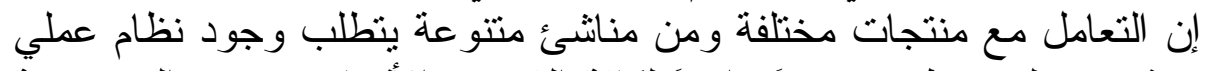

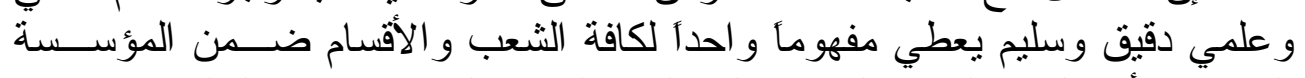

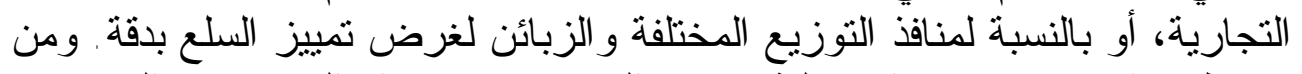

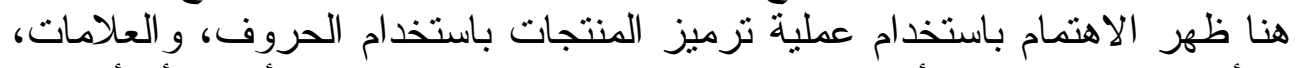

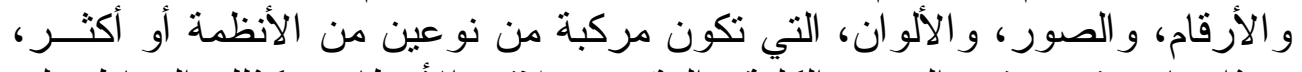

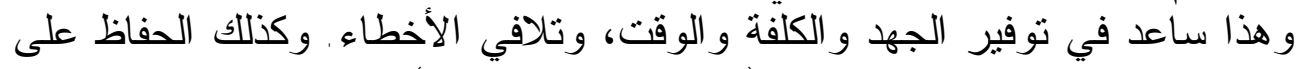

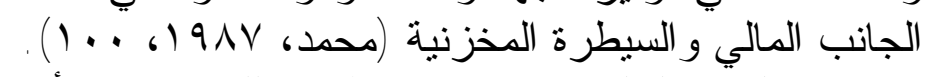

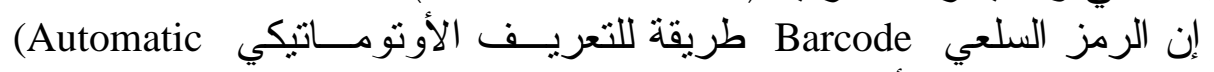

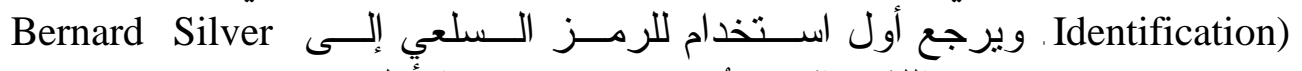

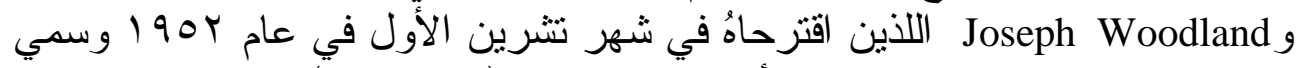

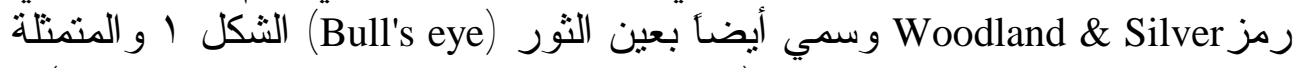
بدو ائر منمركزة حول نقطة و احدة. (www.invetors.about.com/mbiopage.html).

\section{الثكل 1}

عull's eye عين الثور

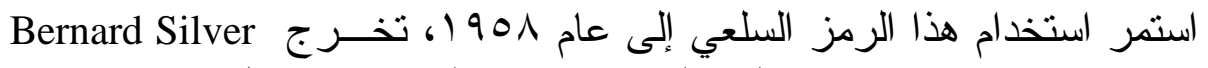

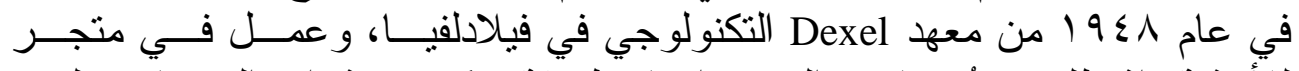

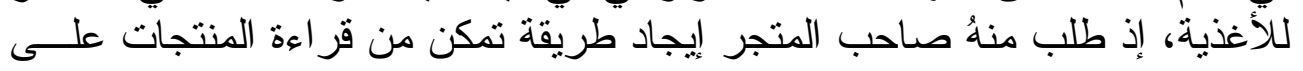




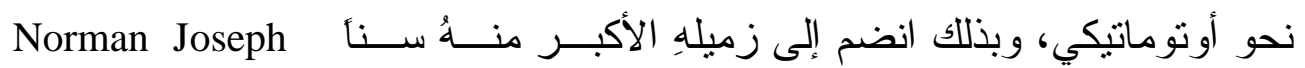
Woodland التصنيف فقط (www.invetors/MaryBellis.page.html).

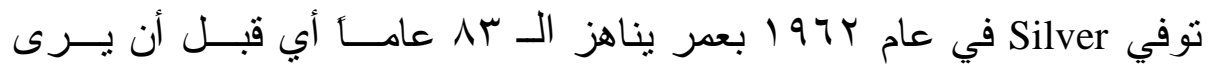

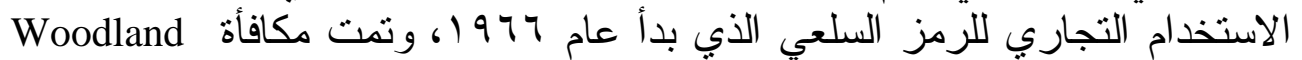

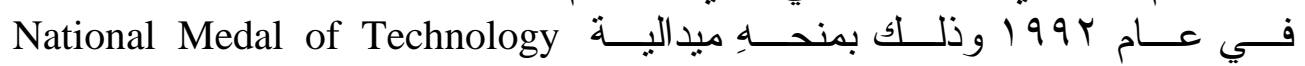

. (www.evrytype.com/standards/og/ogmhare)

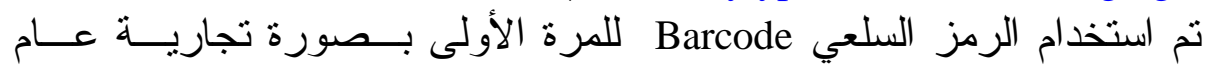

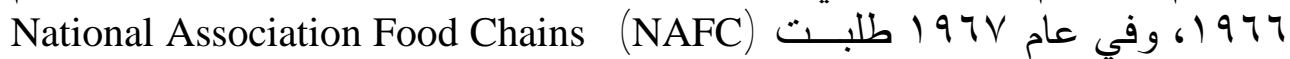

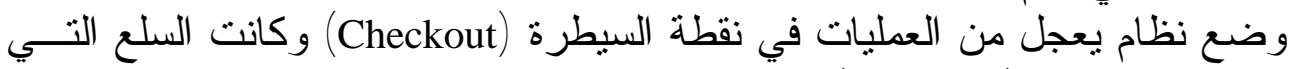

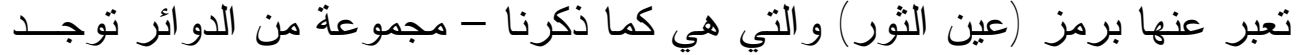

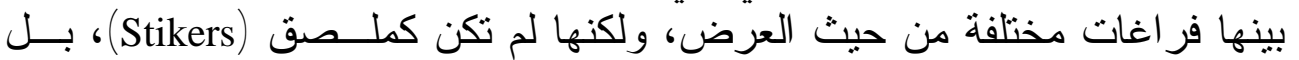

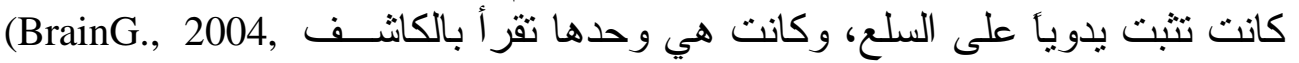

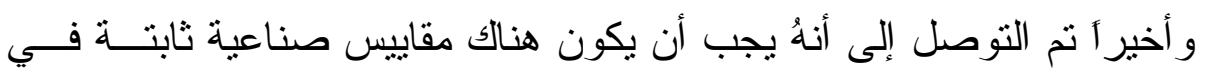

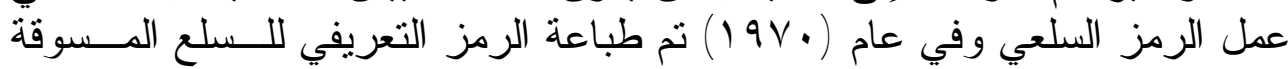

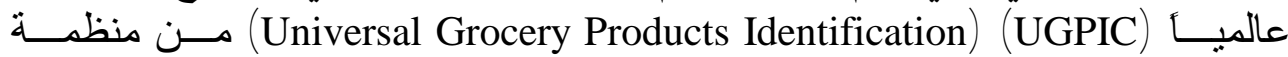

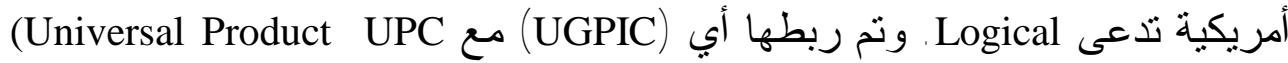

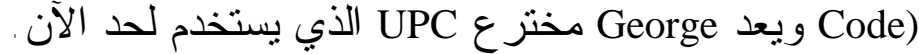

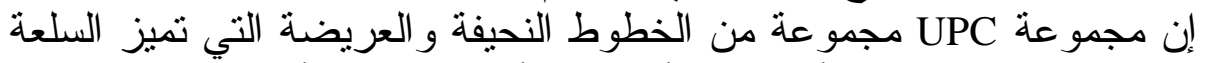

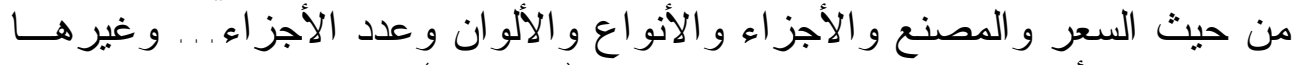
التي يمكن قر أتها من خلال ماسح الكترونسي (Dibb \& Others, 1994, (Scanner)

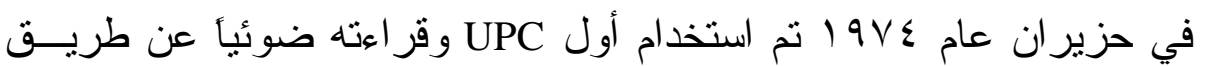

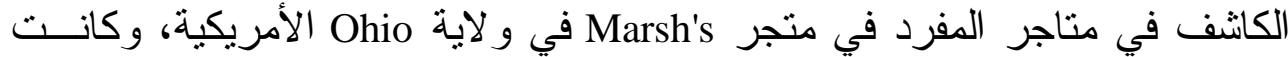

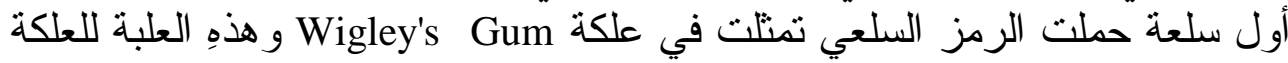

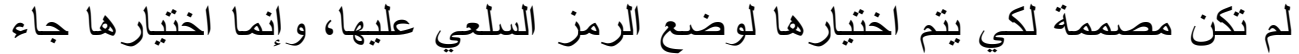

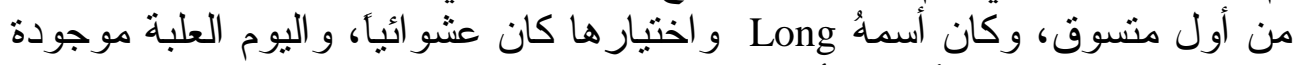
في المتحف الوطني للتأريخ الأمريكي.

Smithsonian Institution's National Museum of American History (www.everytyee.com/standards/og/logmhare.html).

إن الحدث الحقيقي و المهم الذي تم العمل بـاء باستخدام الرمز السلعي في جميع

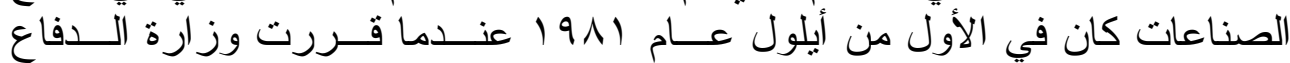

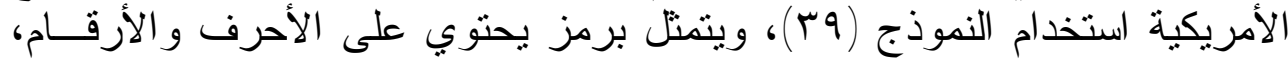

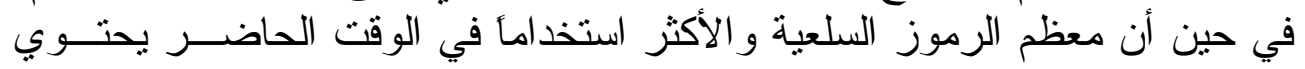




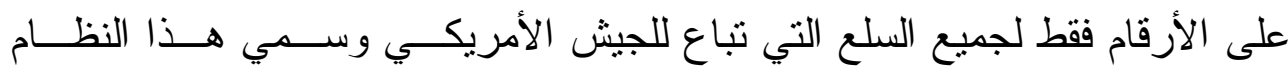

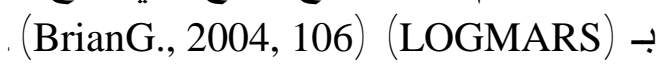

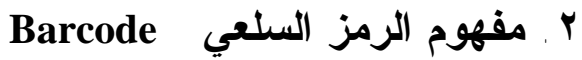

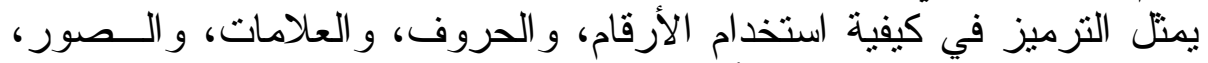

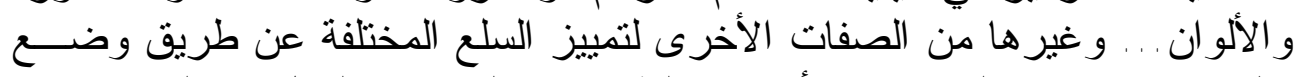

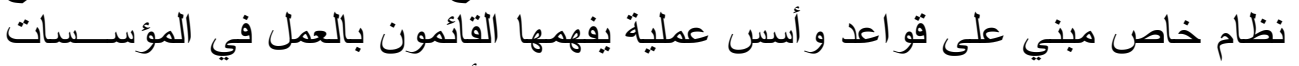

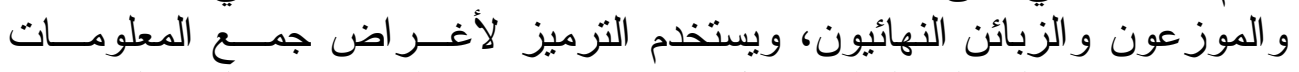

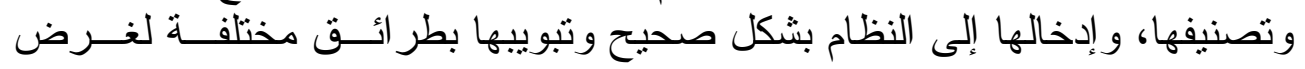

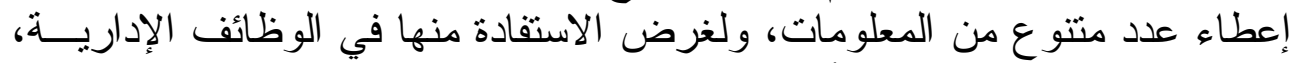

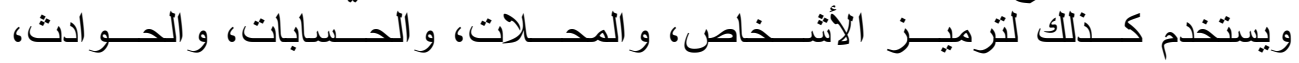

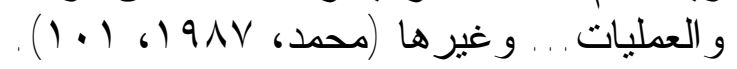

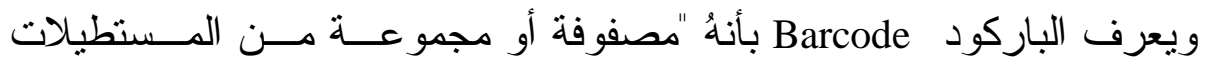

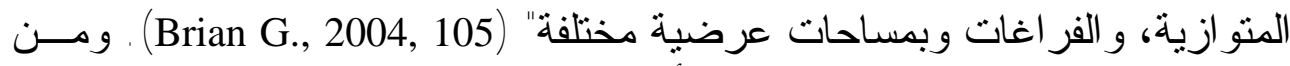

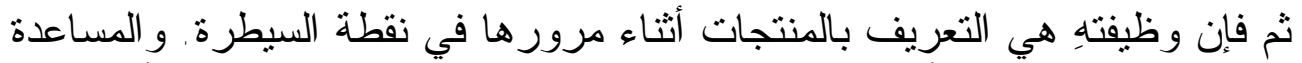

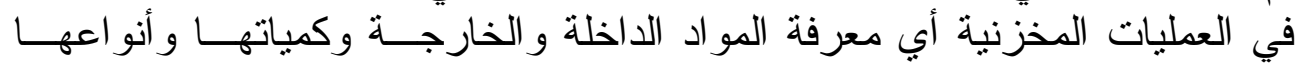
ومو اصفاتها، و هذا يؤدي إلى تسريع العمليات الإدارية و الصناعية و التسية التسويقية.

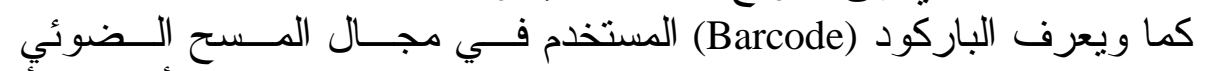

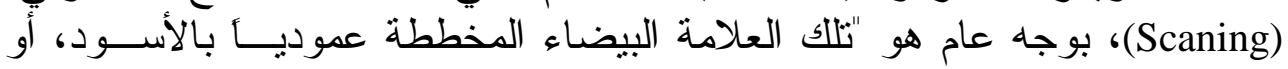

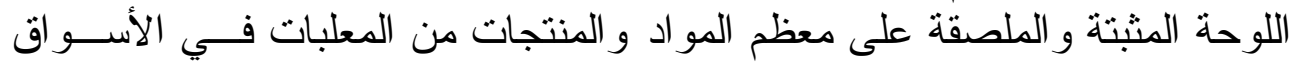

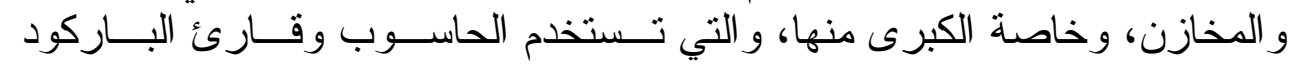
(Barcode Reader)

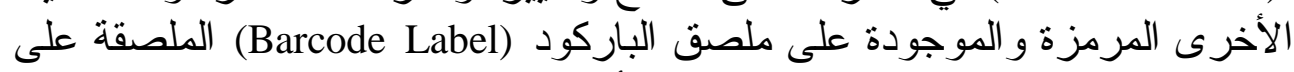

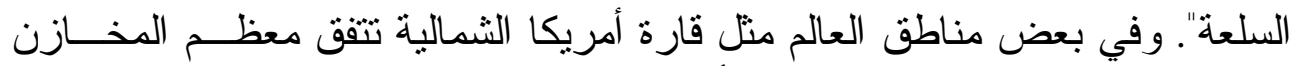

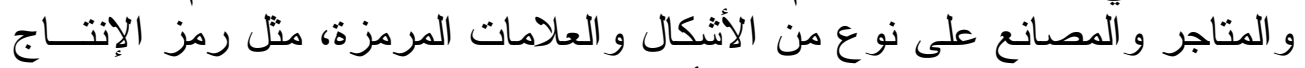

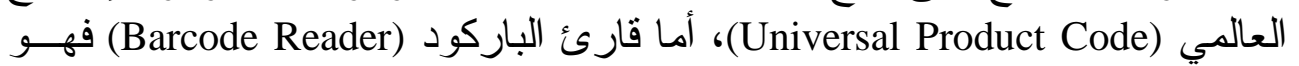

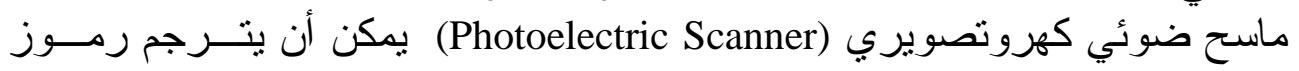
، الباركود إلى رموز رقميــة (Translates Barcode Symbols Into Digital Code)

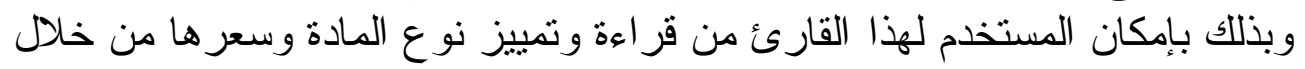

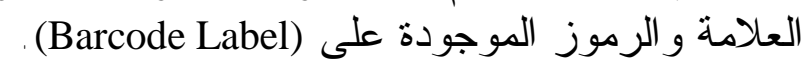

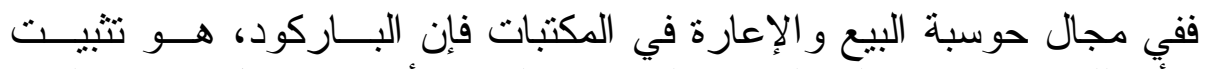

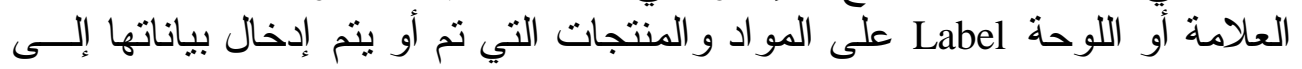

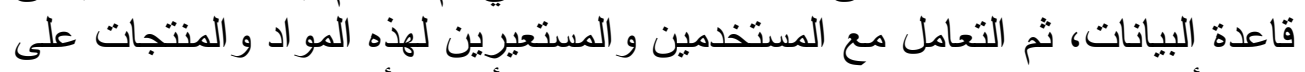

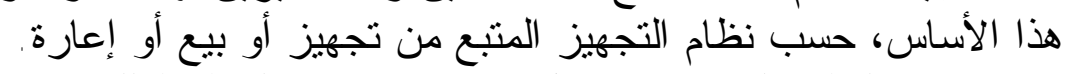

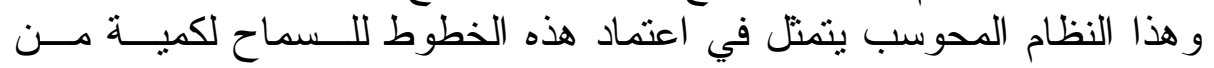

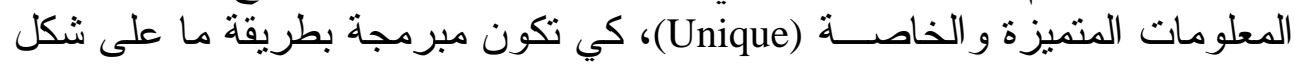


أعمدة بمكن قر اعتها بدقة وبسر عة وبوسائل قر اعة وماسحات تـــرتبط بالحو اســـبـ.

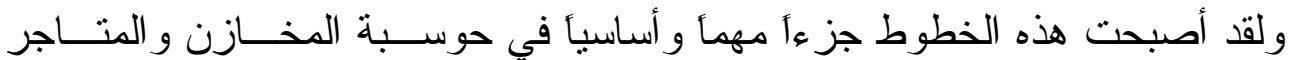

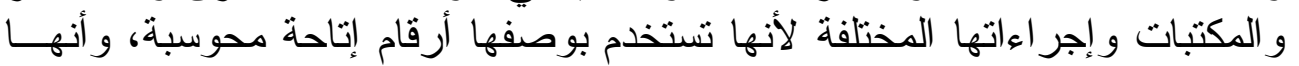

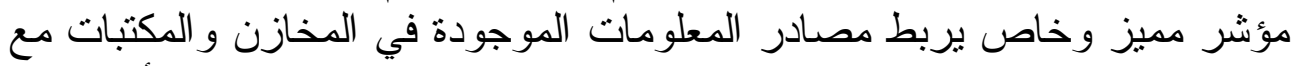

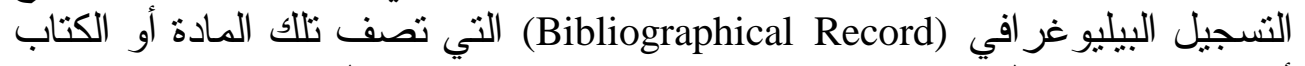
أو المجلةو هكذا. (Www.google.com/search/barcodes.html)

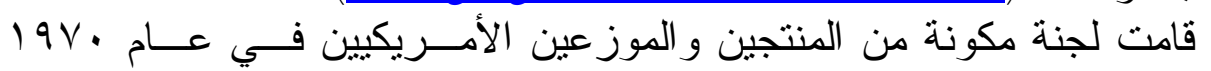

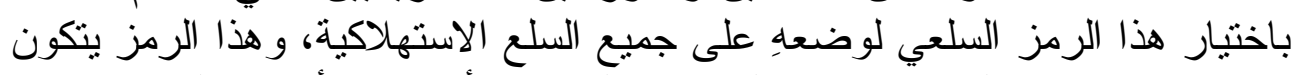

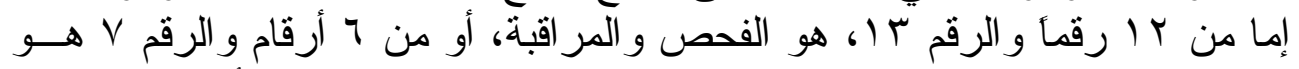

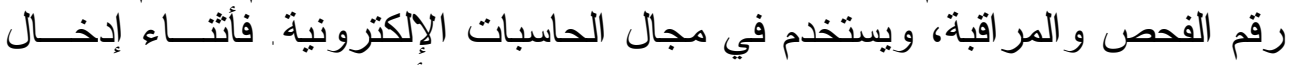

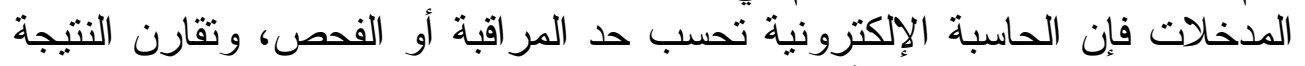

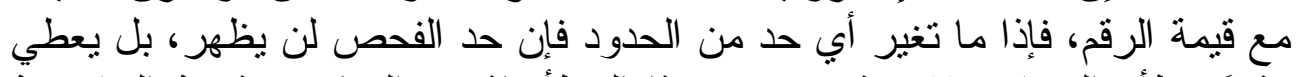

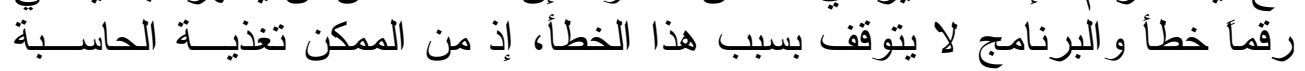
الإكترونية بالمعلومات لتستمر وتحذف العناصر التهات التي فيها أخطاء و هكذا. و والأرقام

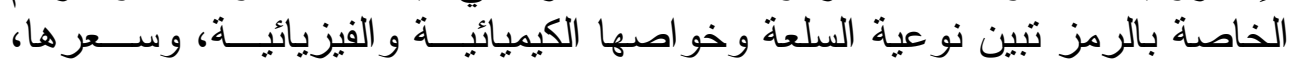

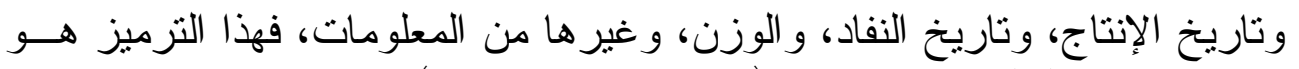

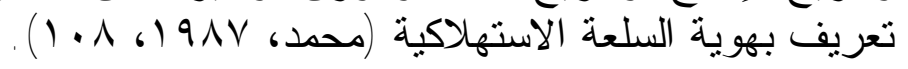

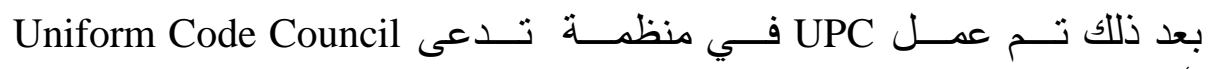
(UCC)

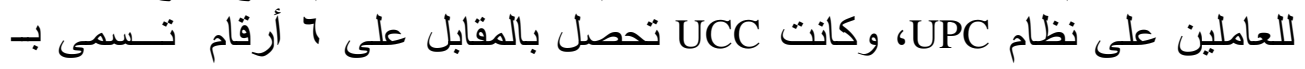
Manufacturer Identification Number

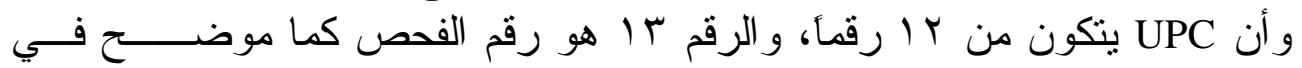

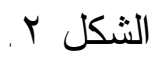

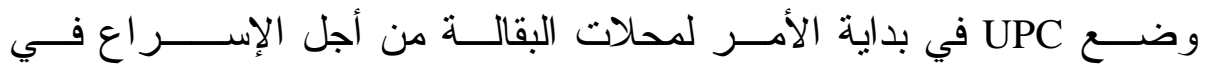

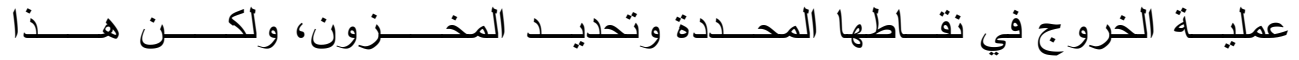

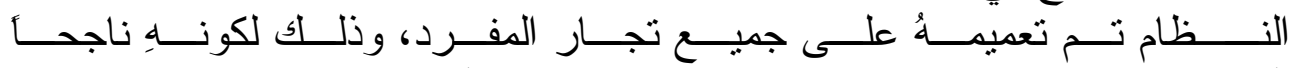
. (www.electronics.howstuffworks.com/UPC.html) 


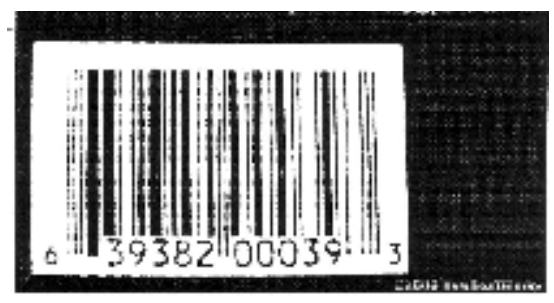

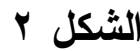 \\ الرمز السلعي}

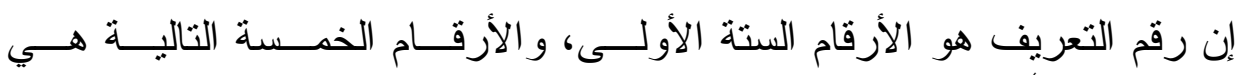
(Item Number)

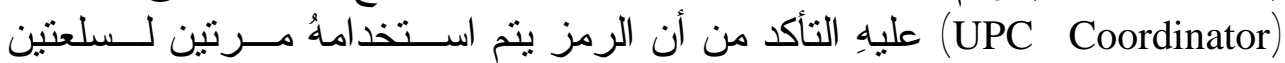

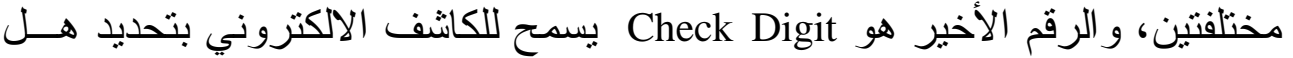

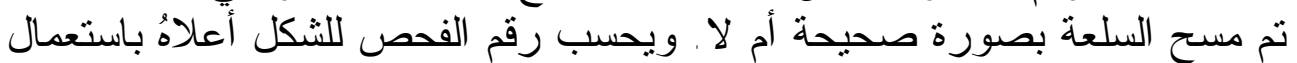

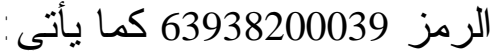

$6+9+8+0+0+9=32$ ا ـ جمع القيم لجميع الأرقام في المنازل الفردية

$32 * 3=96$

$$
\text { r ( برب الناتج في ب }
$$

$3+3+2+0+3=11$

$$
\text { r. جمع القيم لجميع الأرقام في المنازل الزوجية }
$$$$
\text { ع . جمع هذا الناتج مع الناتج في الخطوة r }
$$

$96+11=107$

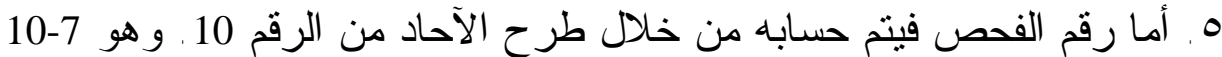

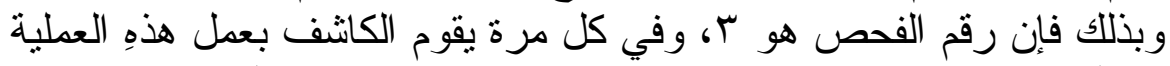
لكل سلعة (www. Electronics.howstuffworks.com/UPS1.html) .

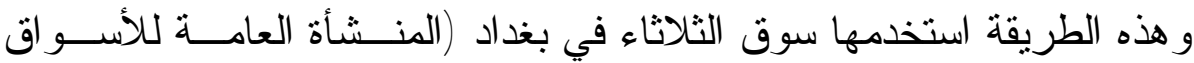
المركزية)، وهي واحدة من الطرق الحسابية لإيجاد رقم الفحص (محمـد، INV

انتشر استخدام الرمز السلعي في جميع أنحاء العالم بصيغة موحــدة، فمــثلا

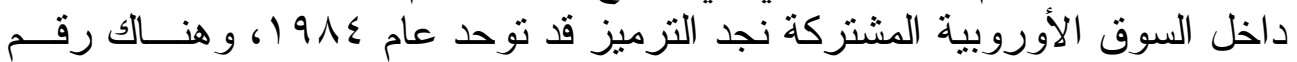

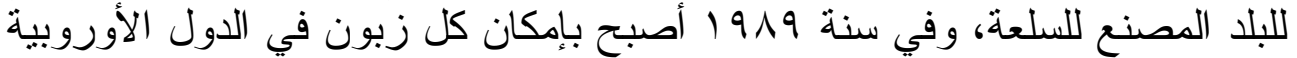

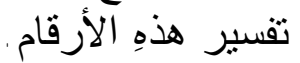

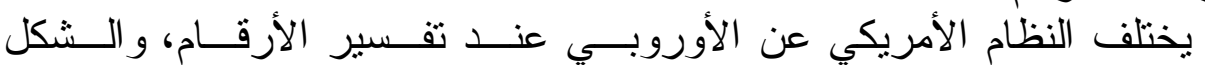
ب يضم رمزين لسلعتين الأولى من الو لايات المتحدة الأمريكية (أ) و الثانية فرنسية 


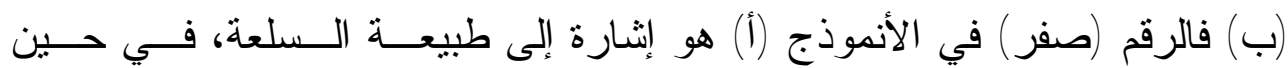

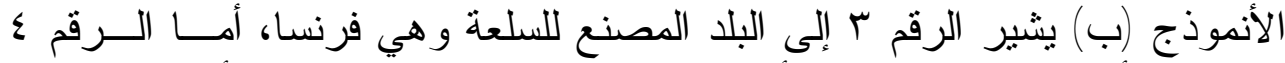

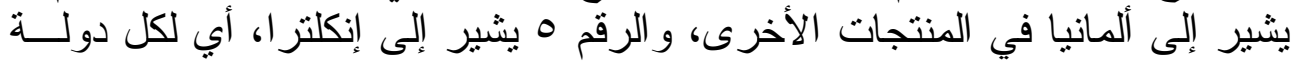

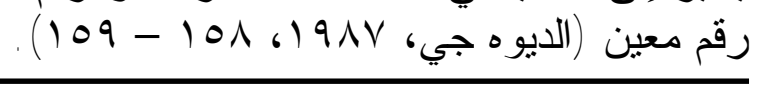

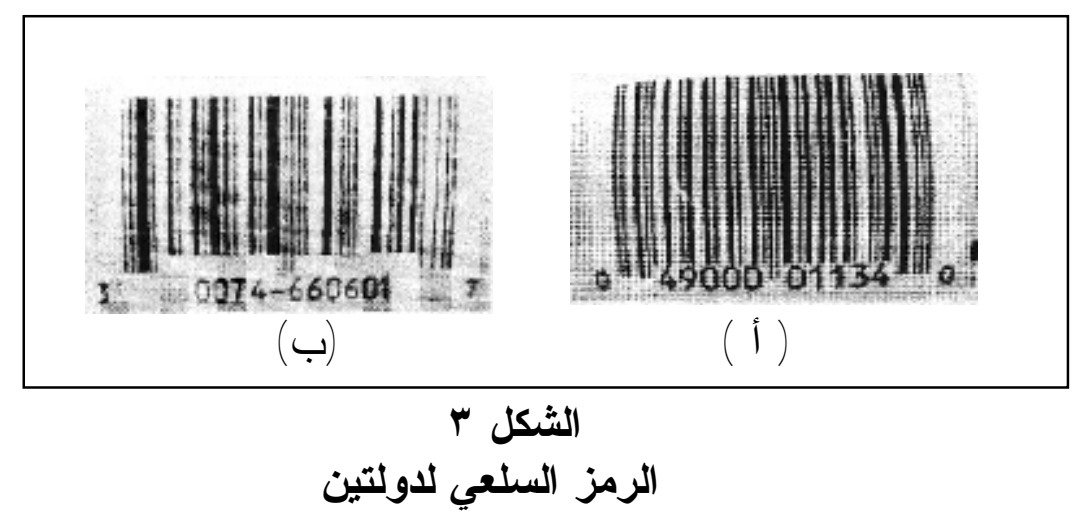

يتكون النظام UPC من خطوط عمودية يكون على شكل مجموعتين: الأولى وقلى

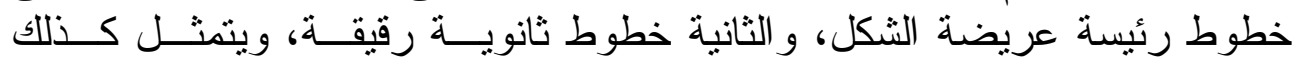

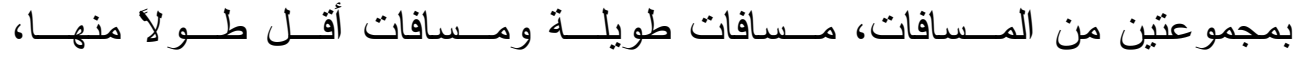

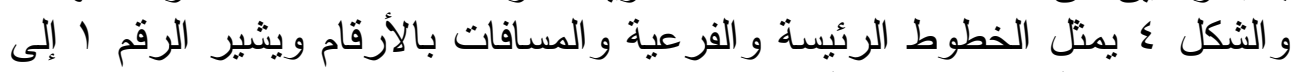
الخط الرئيس (المسافة الكبيرة).

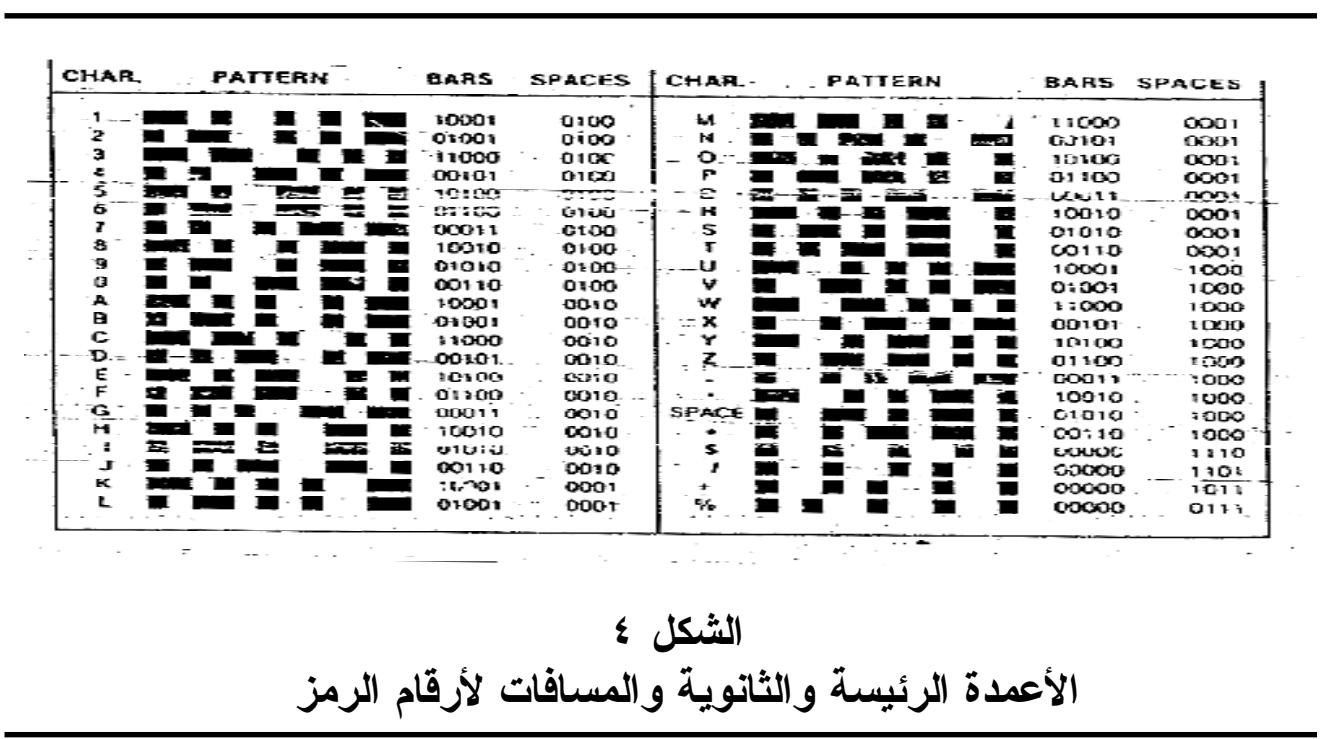

إما (الصفر ) فيشير إلى الخط الثانوي (المسافة القصيرة)، ولنأخذ رقم ا مثالا على ذللك. إذ رقم ا من الثكل ه يبين الأعمدة و المسافات. 


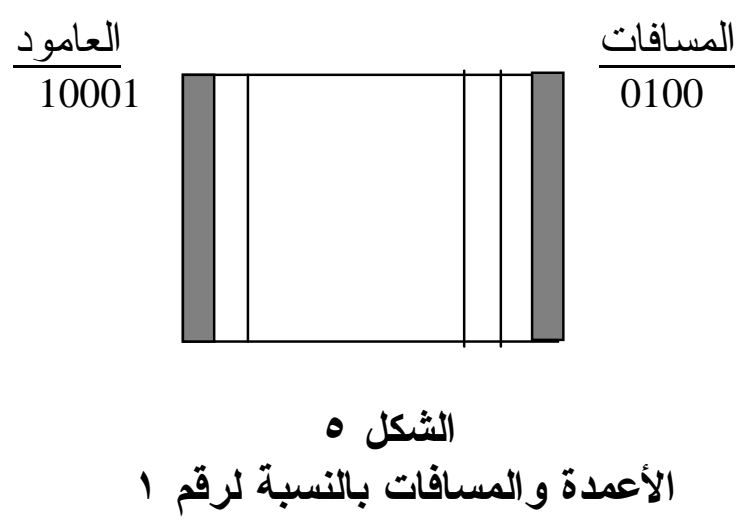

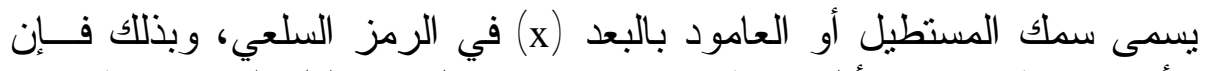

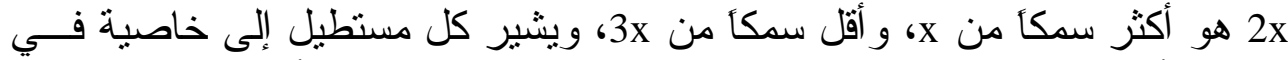

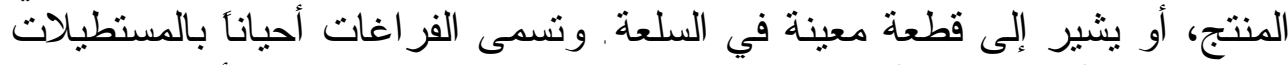

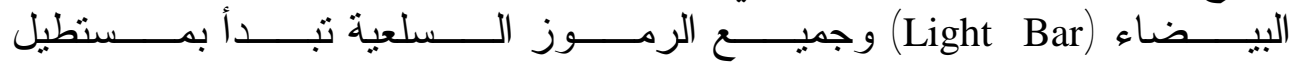

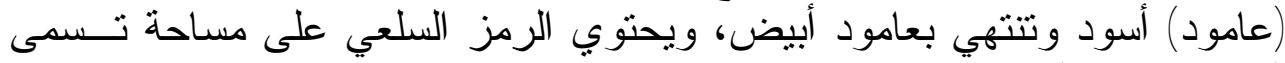
هي مساحة بيضاء توجد حول الرمز السلعي تمكن الماستح الضوني الرئي (Quite Zone) (Scanner)

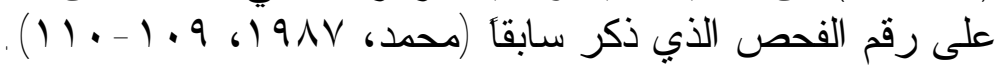

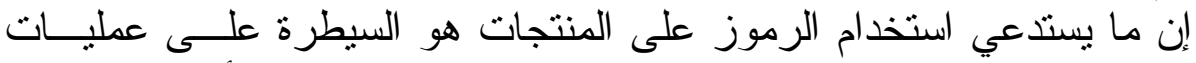

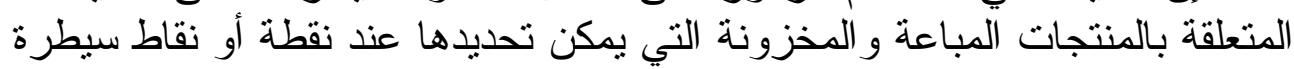

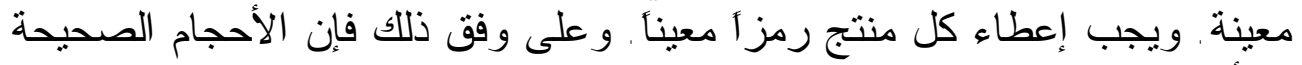

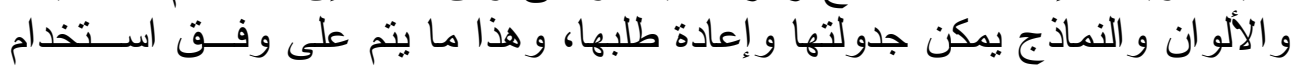

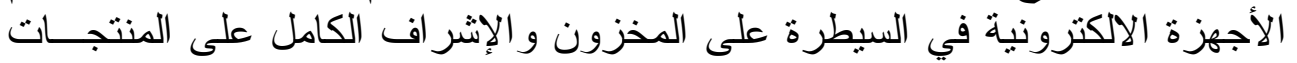

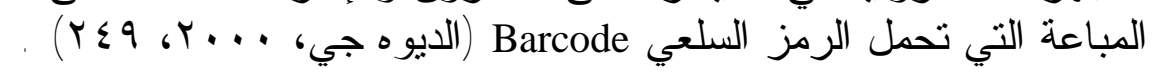

\section{أنموذج بناء الأرقام وتمثيلها بشكل أعمدة أرباء} يوضح الجدول ا أنموذج بناء الأرقام المستخدمة بكاء في تعريف وحدات التجزئة،

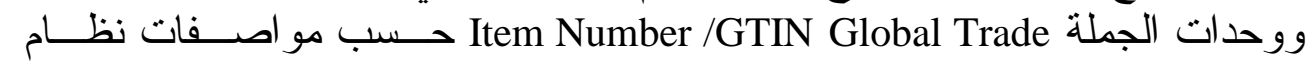




\section{الجدول الجزية}

\section{التعريف بوحدات التجزئة ول الجملة}

\begin{tabular}{|c|c|c|c|c|c|c|c|c|c|c||c|c||c|l|}
\hline \multicolumn{10}{|c|}{ 14-digit Global Trade Item Number (GTIN) } & Numbering Structures \\
\hline $\mathrm{T}_{14}$ & $\mathrm{~T}_{13}$ & $\mathrm{~T}_{12}$ & $\mathrm{~T}_{11}$ & $\mathrm{~T}_{10}$ & $\mathrm{~T}_{9}$ & $\mathrm{~T}_{8}$ & $\mathrm{~T}_{7}$ & $\mathrm{~T}_{6}$ & $\mathrm{~T}_{5}$ & $\mathrm{~T}_{4}$ & $\mathrm{~T}_{3}$ & $\mathrm{~T}_{2}$ & $\mathrm{~T}_{1}$ & \\
\hline $\mathrm{N}_{13}$ & $\mathrm{~N}_{12}$ & $\mathrm{~N}_{11}$ & $\mathrm{~N}_{10}$ & $\mathrm{~N}_{9}$ & $\mathrm{~N}_{8}$ & $\mathrm{~N}_{7}$ & $\mathrm{~N}_{6}$ & $\mathrm{~N}_{5}$ & $\mathrm{~N}_{4}$ & $\mathrm{~N}_{3}$ & $\mathrm{~N}_{2}$ & $\mathrm{~N}_{1}$ & 0 & EAN/UCC-13 \\
\hline $\mathrm{N}_{12}$ & $\mathrm{~N}_{11}$ & $\mathrm{~N}_{10}$ & $\mathrm{~N}_{9}$ & $\mathrm{~N}_{8}$ & $\mathrm{~N}_{7}$ & $\mathrm{~N}_{6}$ & $\mathrm{~N}_{5}$ & $\mathrm{~N}_{4}$ & $\mathrm{~N}_{3}$ & $\mathrm{~N}_{2}$ & $\mathrm{~N}_{1}$ & 0 & 0 & UCC-12 \\
\hline $\mathrm{N}_{8}$ & $\mathrm{~N}_{7}$ & $\mathrm{~N}_{6}$ & $\mathrm{~N}_{5}$ & $\mathrm{~N}_{4}$ & $\mathrm{~N}_{3}$ & $\mathrm{~N}_{2}$ & $\mathrm{~N}_{1}$ & 0 & 0 & 0 & 0 & 0 & 0 & EAN/UCC-8 \\
\hline
\end{tabular}

Source: (www.ean.jedco.gov.jo/barcode-steps-a.htm)

\section{تمثيل نماذج الأرقام في شكل أعمدة (باركود) Barcode Symbol}

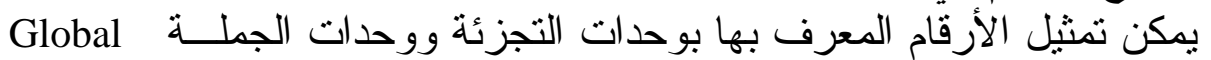

Trade Item Number /GTIN

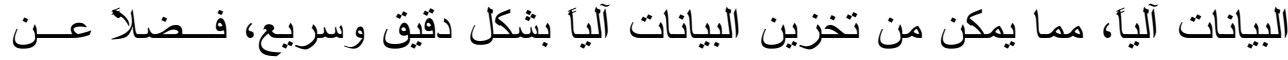

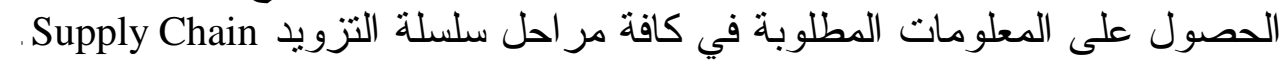

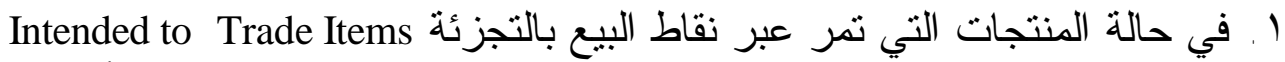
بتم تعريف المنتجات باستخدام نماذج الأرقـام EAN/UCC-13, UCC-12, EAN/UCC-8

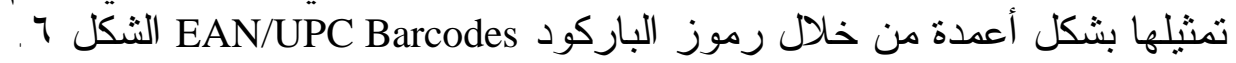
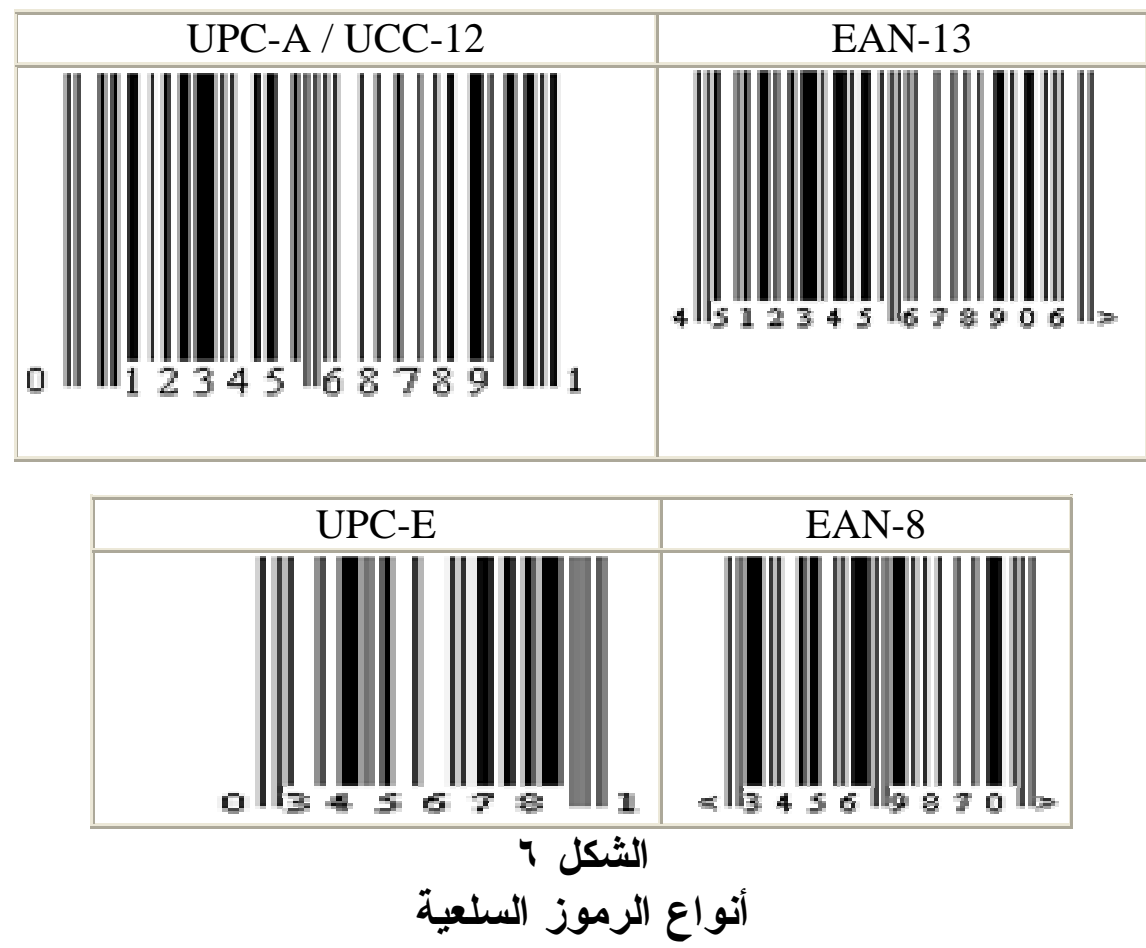

Source:(www.ean.jedco,Op.cit) 


\section{المهتدي [roq]}

rems Not Intended to Trade r المنتجات التي لا تمر عبر نقاط البيع بالتجزئة Cross the Retail Point of Sale

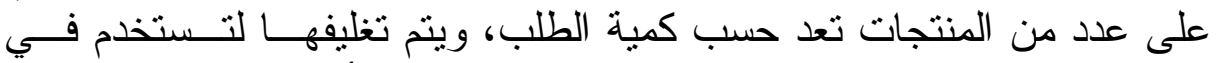

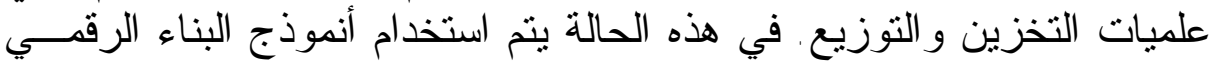

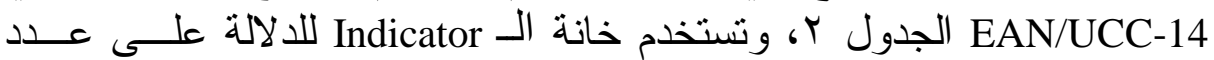

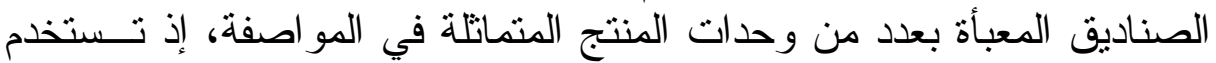

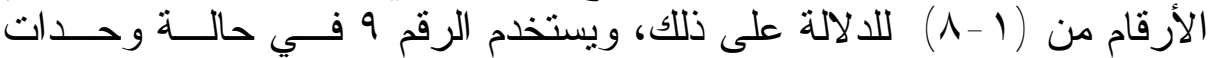
المنتج غير المتماثلة و المعبأة داخل العلبة.

\begin{tabular}{|c|c|c|c|c|c|c|c|c|c|c|c|c|c|c|}
\hline \multicolumn{15}{|c|}{ 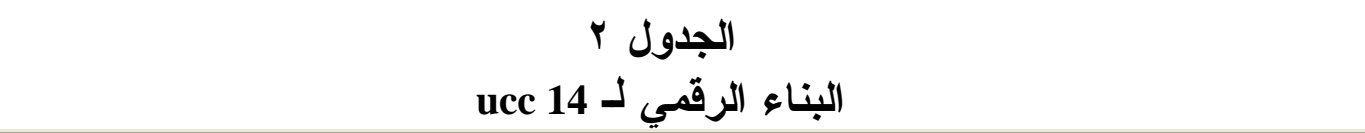 } \\
\hline \multicolumn{15}{|c|}{ EAN/UCC-14 identification number (GTIN) } \\
\hline $\begin{array}{l}\text { Check } \\
\text { digit }\end{array}$ & \multicolumn{12}{|c|}{$\begin{array}{l}\text { EAN.UCC GTIN of contained trade item } \\
\text { (without check digit) }\end{array}$} & Indicator & \\
\hline $\mathrm{N}_{14}$ & $\mathrm{~N}_{13}$ & $\mathrm{~N}_{12}$ & $\mathrm{~N}_{11}$ & $\mathrm{~N}_{10}$ & $\mathrm{~N}_{9}$ & $\mathrm{~N}_{8}$ & $\mathrm{~N}_{7}$ & $\mathrm{~N}_{6}$ & $\mathrm{~N}_{5}$ & $\mathrm{~N}_{4}$ & $\mathrm{~N}_{3}$ & $\mathrm{~N}_{2}$ & $\mathrm{~N}_{1}$ & EAN/UCC-14 \\
\hline
\end{tabular}

Source:(www.ean.jedco,Op.cit)

بعد تحديد نوع البناء الرقمي GTIN المستخدم، يتم تمثيل الأرقام باسـتخدام

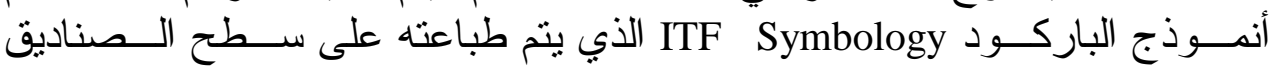

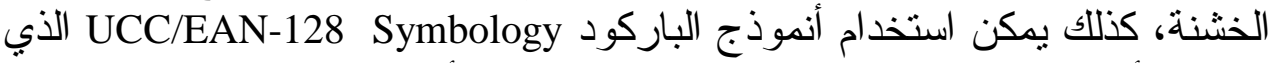

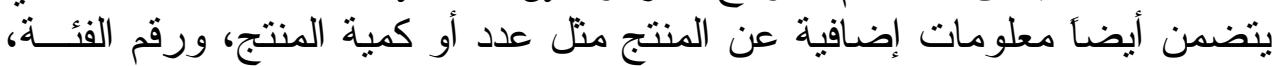

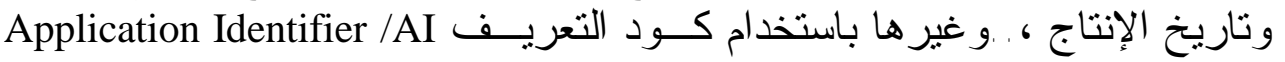




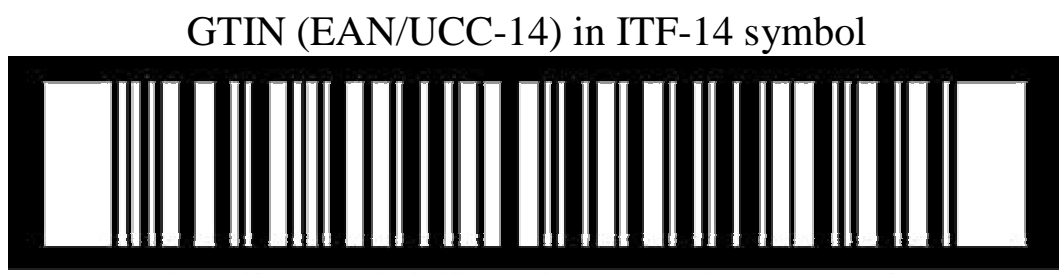

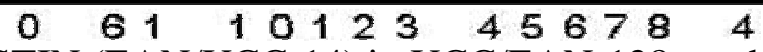

GTIN (EAN/UCC-14) in UCC/EAN-128 symbol

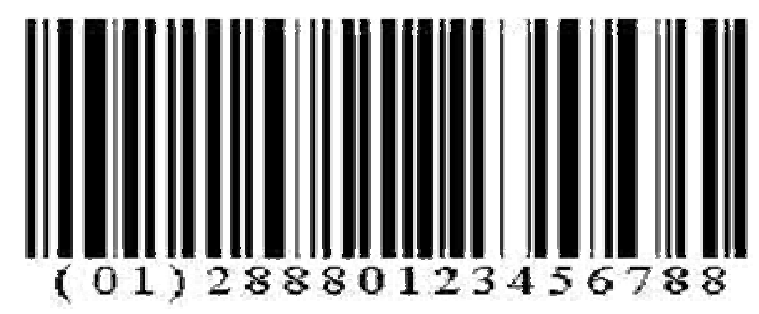

$$
\begin{aligned}
& \text { الثكل vو }
\end{aligned}
$$

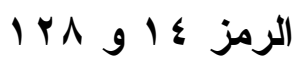

Source:(www.ean.jedco,Op.cit)

$$
\begin{aligned}
& \text { متطلبات استخدام نظام الترميز السلعي وخطواته التطبيقية } \\
& 1 \text { ـ متطلبات استخدام نظام الترميز السلعي ولئي } \\
& \text { يعتمد النظام في عملهِ على التئيز }
\end{aligned}
$$

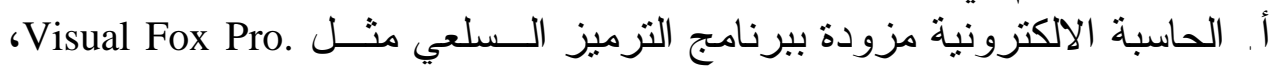

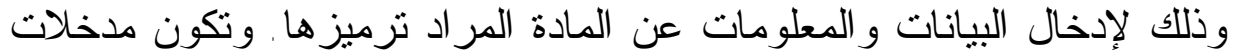

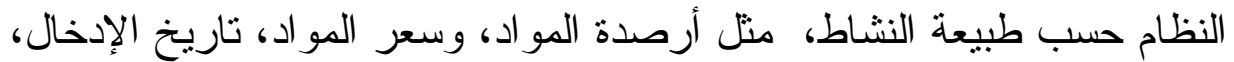

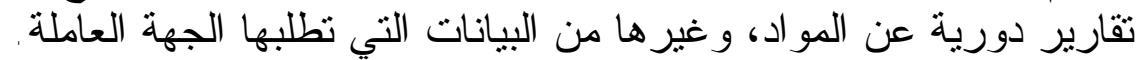

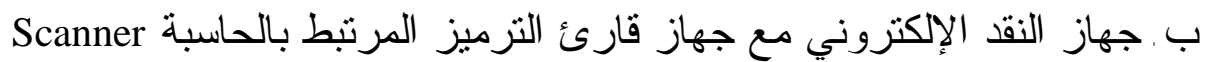

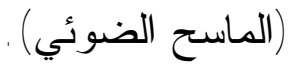

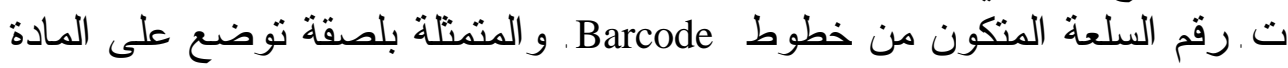

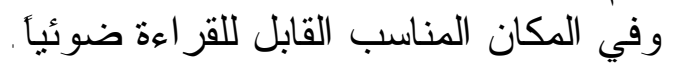

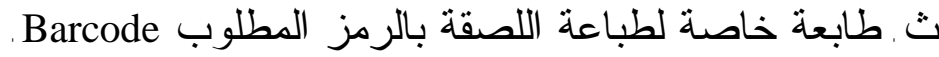

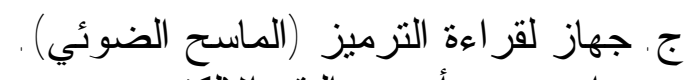

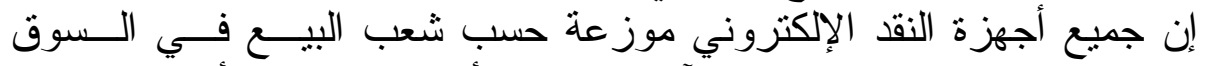

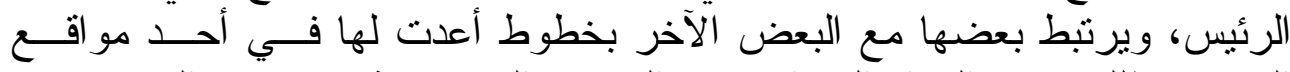
السوق، كذلك جميع المو اد المنو افرة في السوق و المعروضة في شعب البيع تحتوي 


\section{المهتدي [1)}

على علاقةة، وهذِه العلاقةة تحوي رقم المادة التي تكون بشكلين شكل خطوط، وشكل

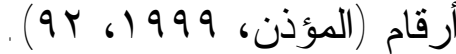

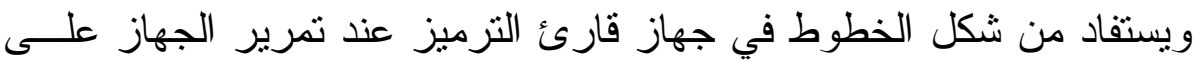

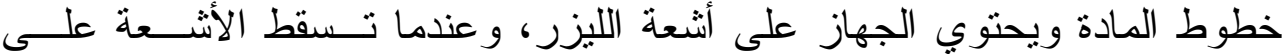

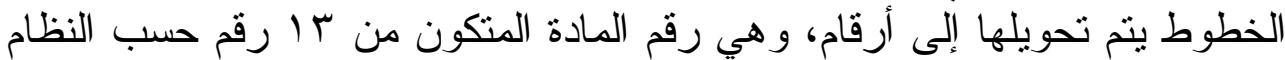

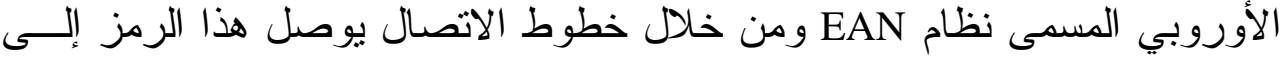

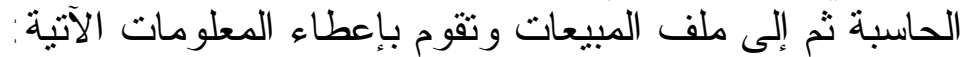

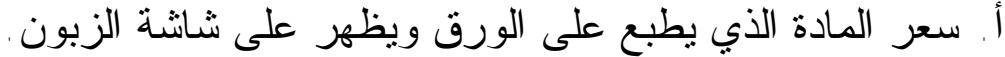

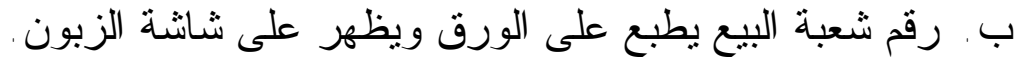

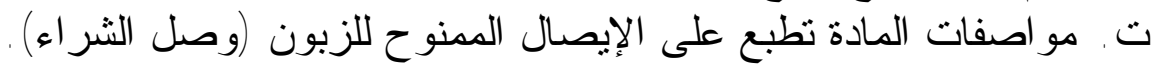

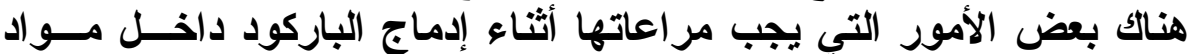

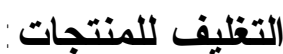

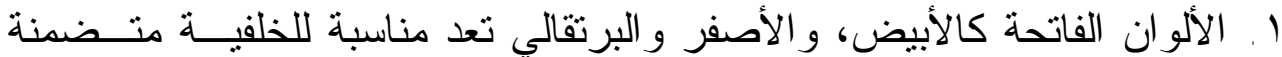

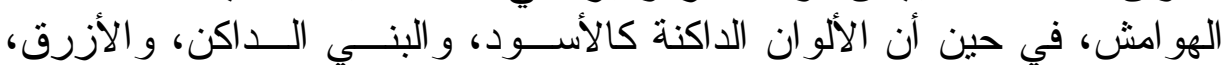

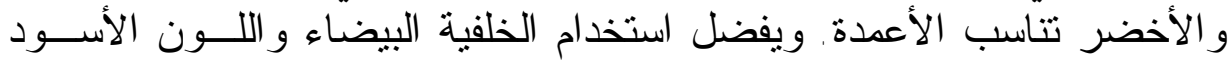

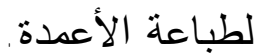

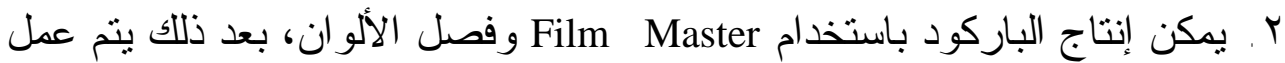

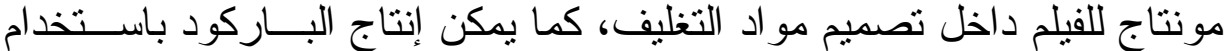

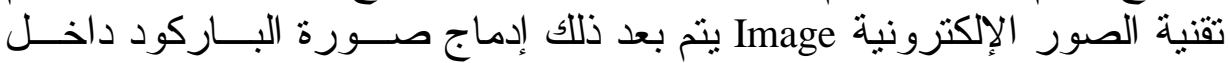

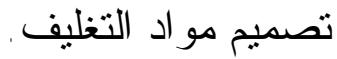
r. لا يصلح إنتاج الباركود على ورق خفيف، أو على ورق أبيض، ثــم مـسحه ضوئيًا.

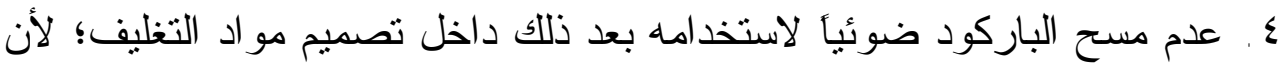

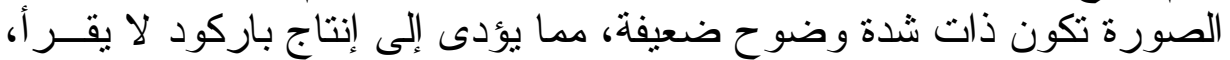

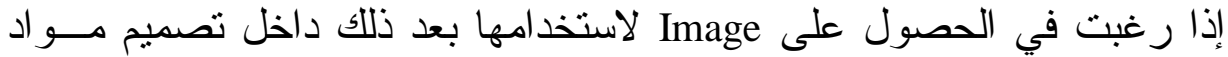
التغليف ينم طلب ذلك من المنظمة المنتجة للأفلام.

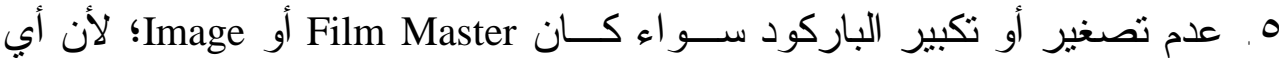

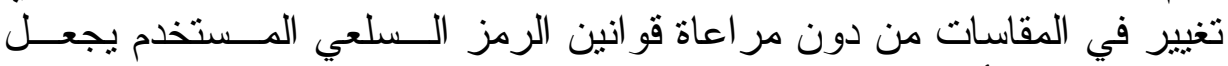

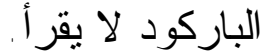

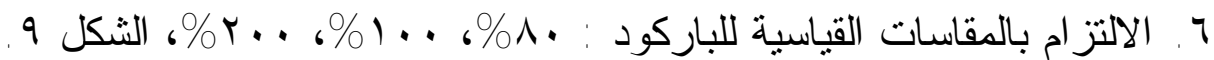

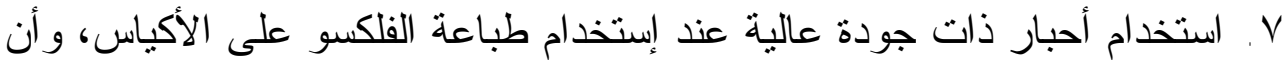

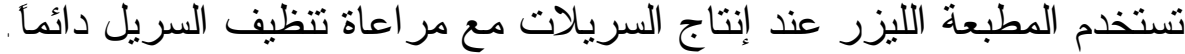
1. استخدام تقنية طباعة ذات شدة وضوح عاليزة عالية.

\section{(www.ean.Jedco.gov.Jo/barcode-quality-a.htm)}




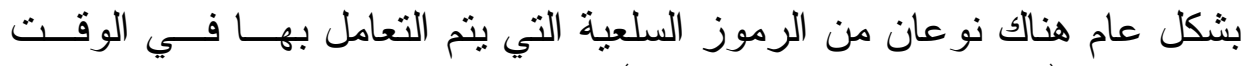
الحاضر وهي (Riasecki, 2003, 207-209):

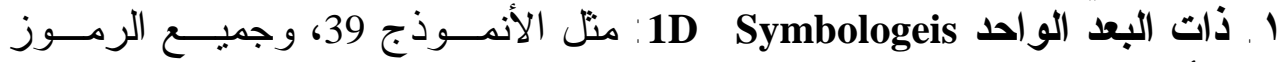

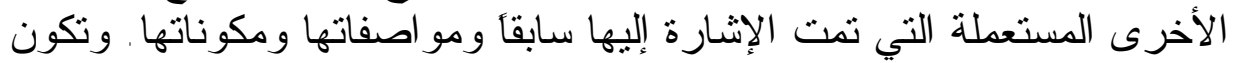

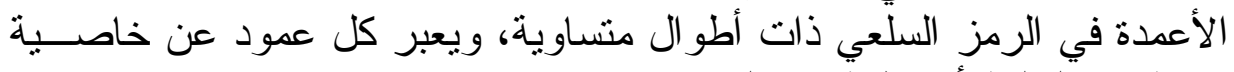

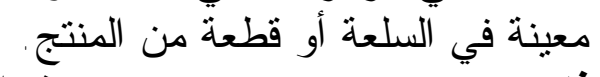

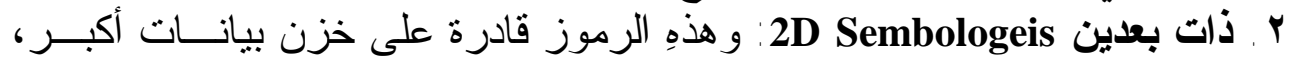

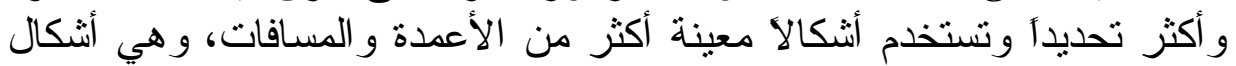

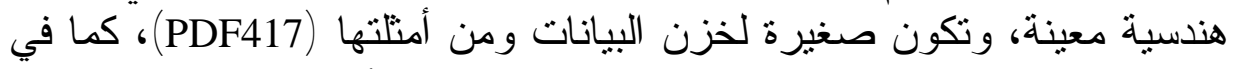

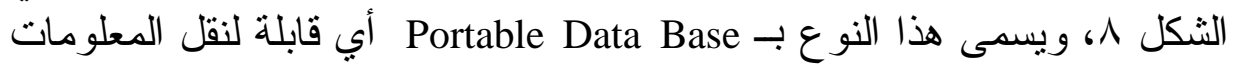

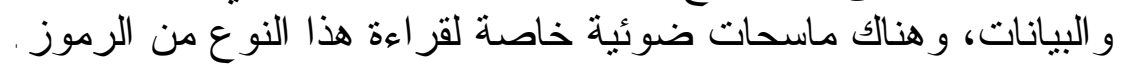

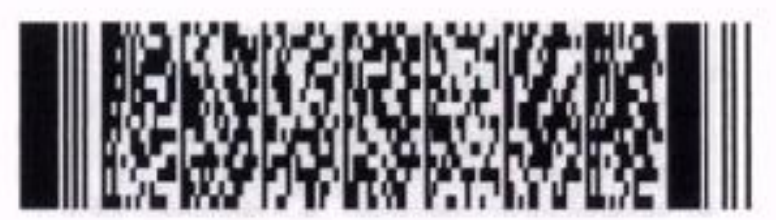

$$
\text { الثنكل } 1 \text { البطن }
$$

(الرموز ذات البعدين PDF 417)

Source:(www.ean.jedco,Op.cit)

r ا الخطوات اللازمة لتطبيق الباركود(")

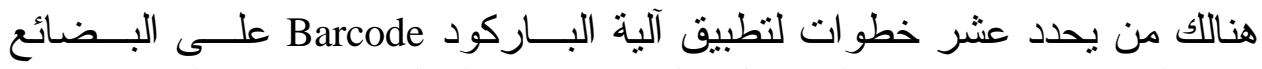

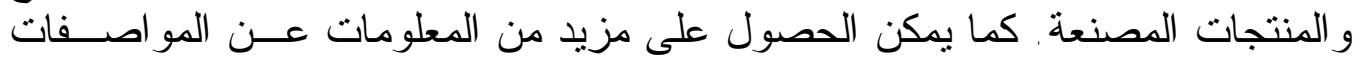

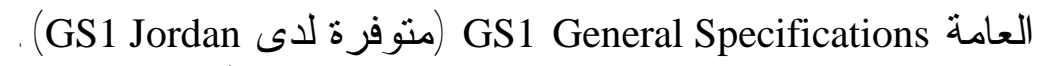
· الخطوة 1 : الحصول على الرمز الخاص بالمنظمة GS1 Prefix Company.

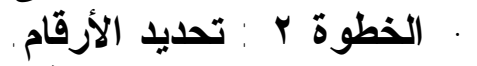

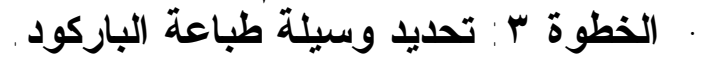

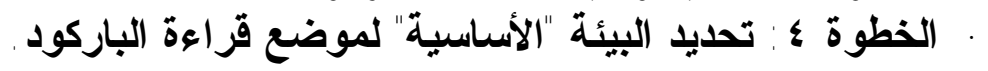

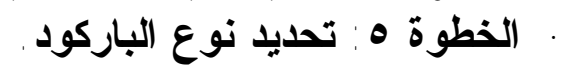

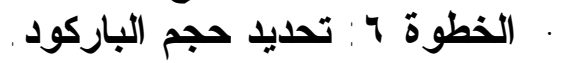

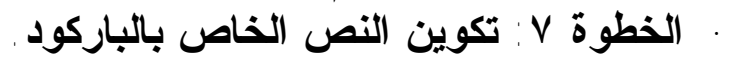
· الخطوة ^: تحديد لون الباركود. 
· الخطوة 9: تحديد مكان وضع الباركود .

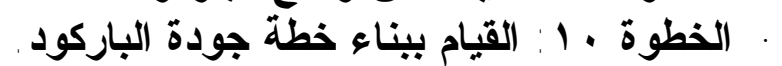
والآتي شرح موجز للنقاط العشر المذكورة آنفاً:

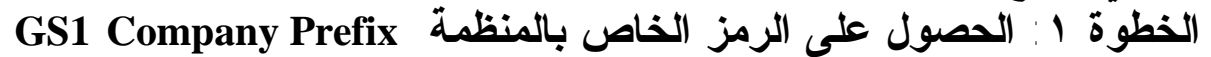

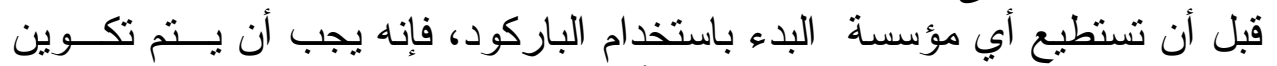

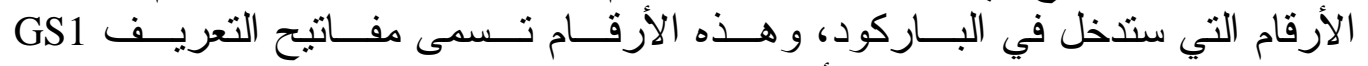

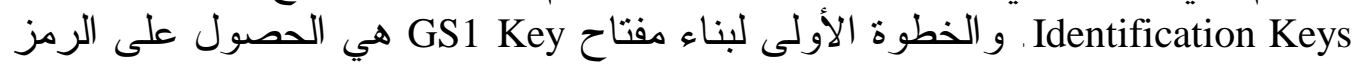

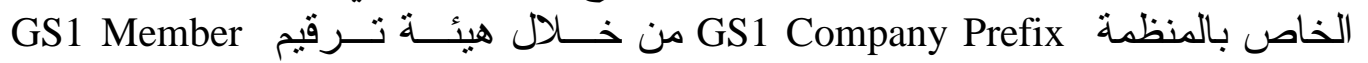
فrganization

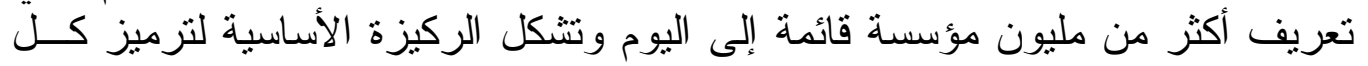

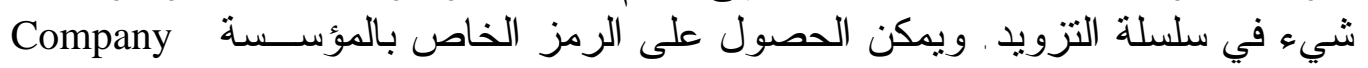
GS1 Prefix الخطوة ب : تحديد الأرقام

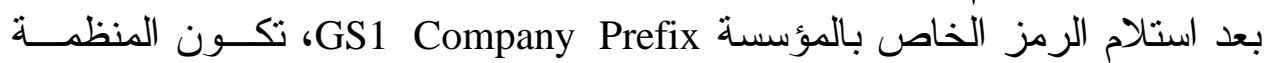

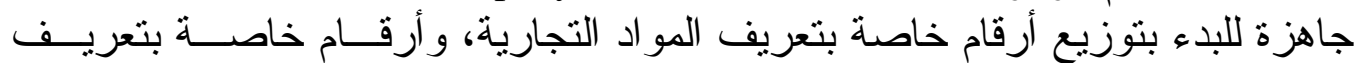

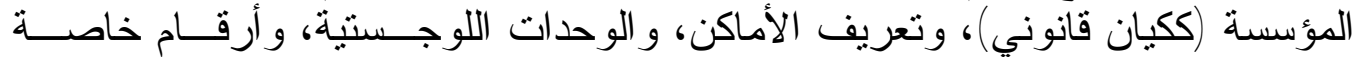

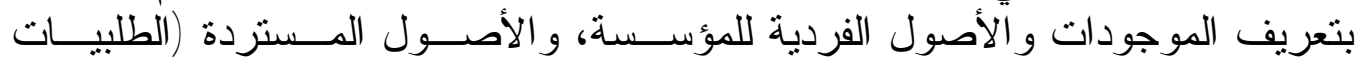

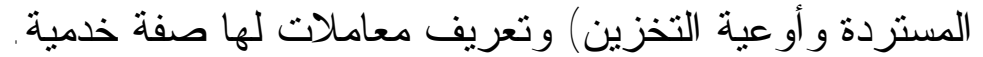

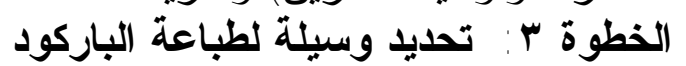

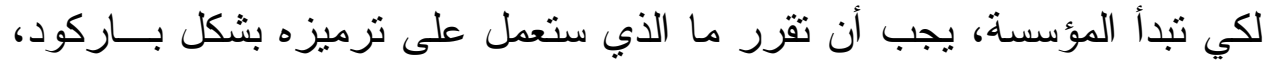

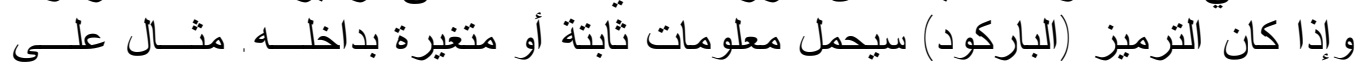

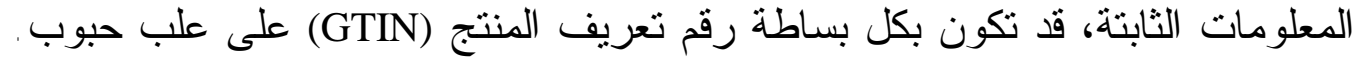

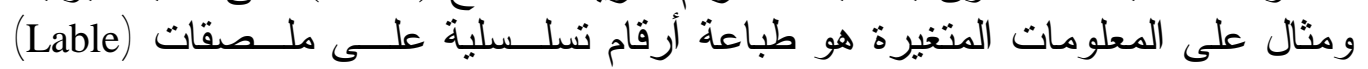
إذا كان الباركود ذا معلومات ثابتة، وكانت المنظمة المنتجة للمنتجات تحتاج إلى في المنتج

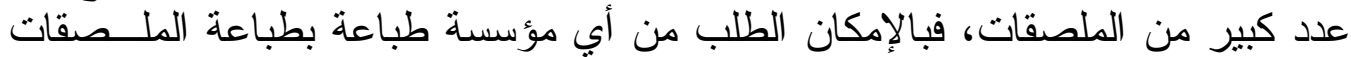

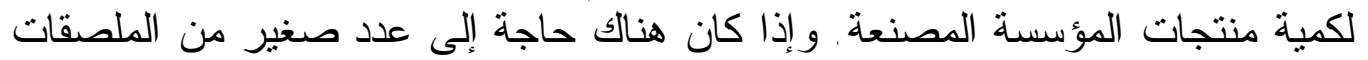

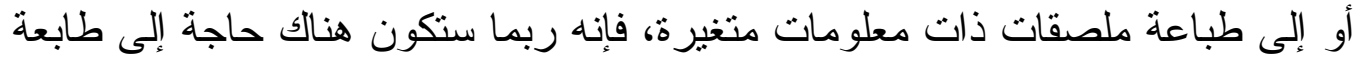

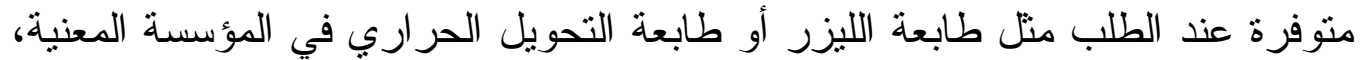
وذللك في وحدات التخزين أو نقاط أخرى من نقاط الإنتاج.

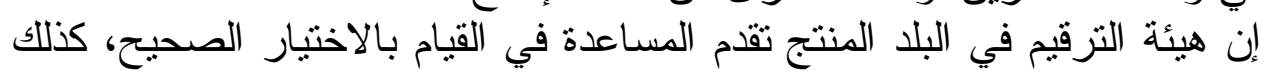

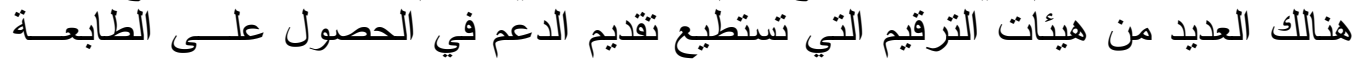
المناسبة.

\section{الخطوة ؛ : تحديد البيئة "ألأسساسية" لموضع قراعة الباركود}

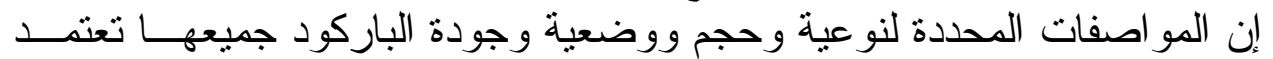
على أين سيتم مسح (قر اعة) الباركود . 
هنالك أربعة سيناريوهات لبيئة المسح (القراعة) الأساسية للمواد التجارية:

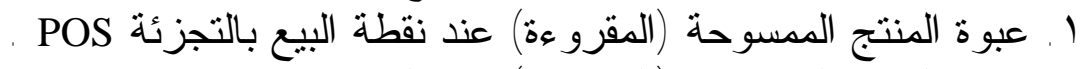

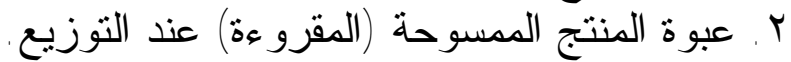

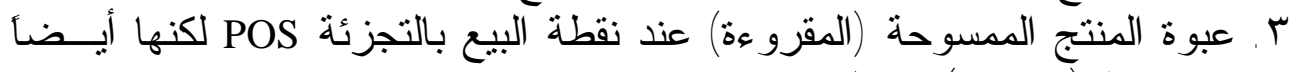

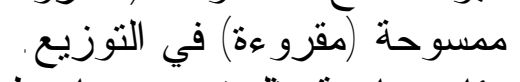

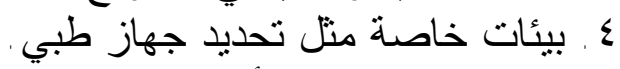

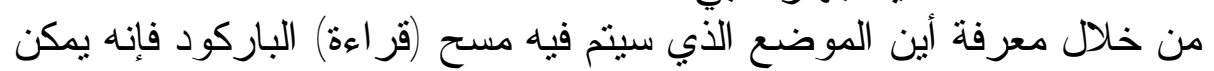

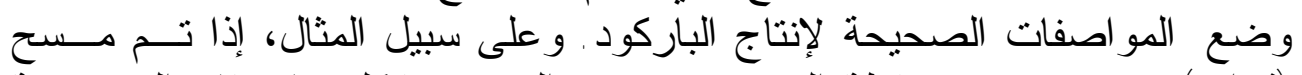

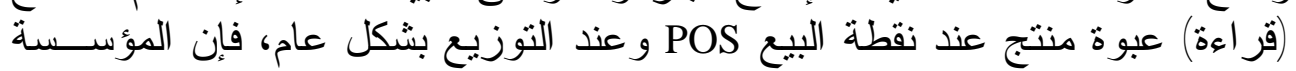

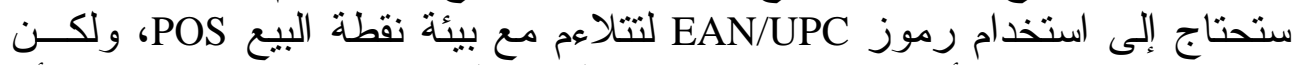

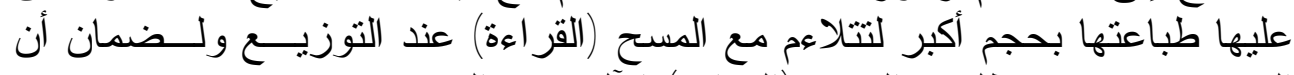

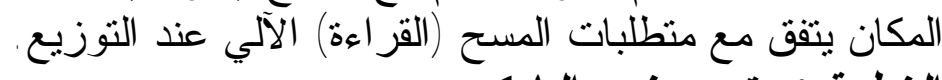

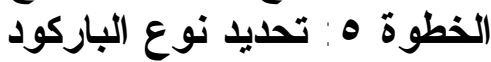

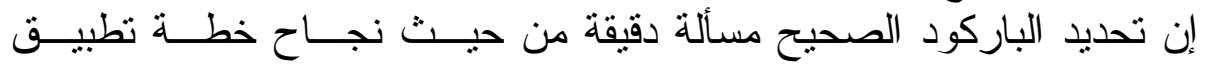

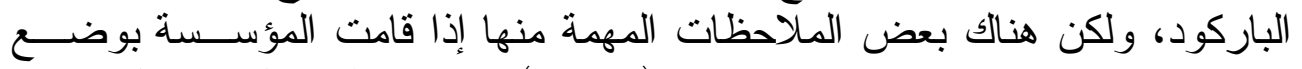

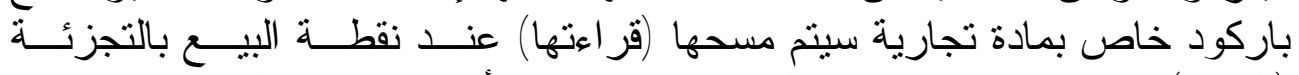

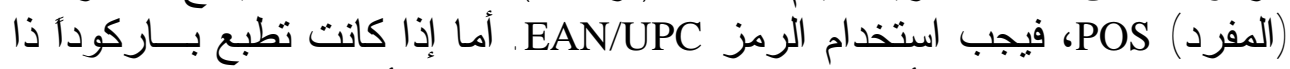

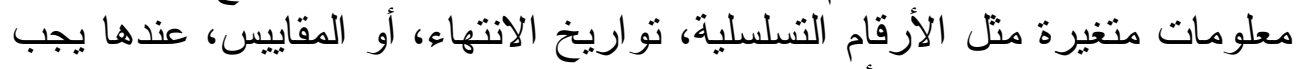

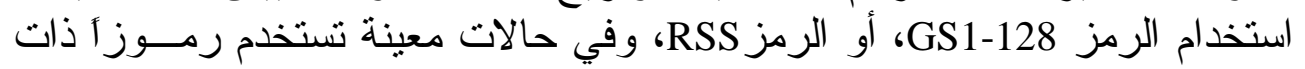

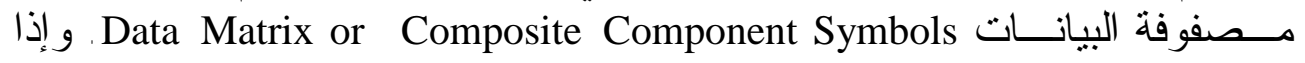

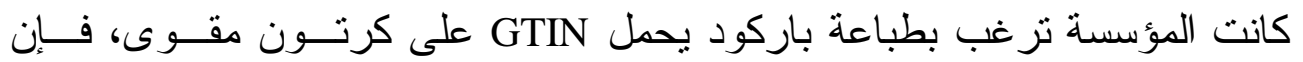

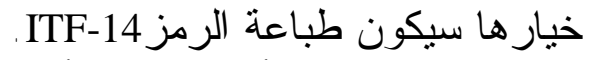

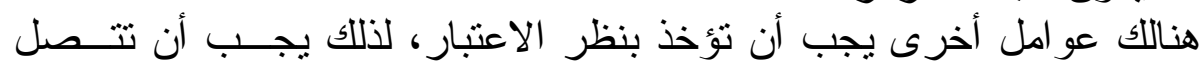

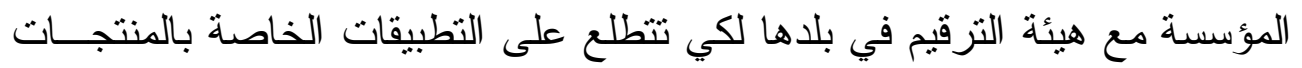

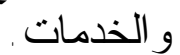

\section{الخطوة ؟ب: تعديد حجم الباركود}

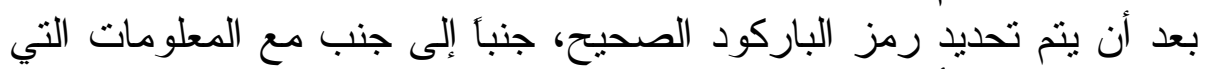

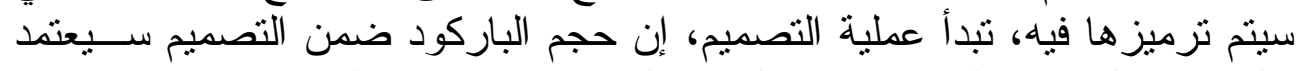

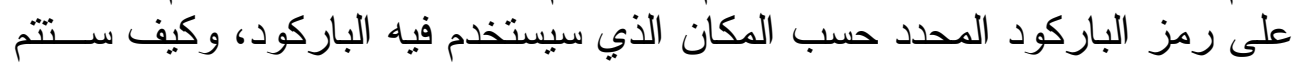

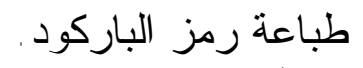

الخطوة V: تكوين النص الخاص بارد بالباركود

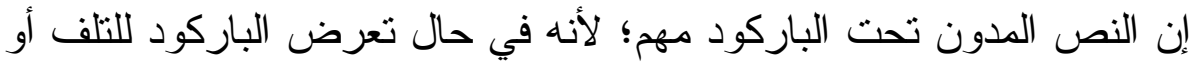

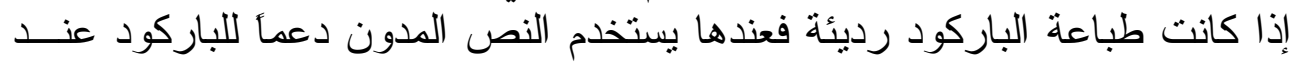

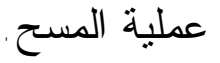




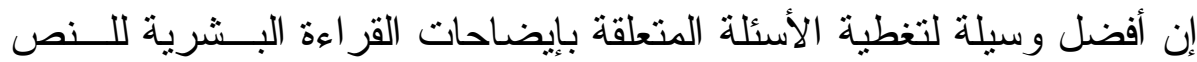

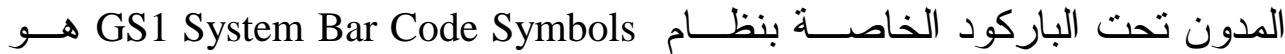

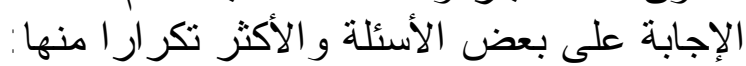

ا ـ هل أن النص الخاص بالقر اعة البشرية يجب النّاء أن يكون عند حجم معين؟

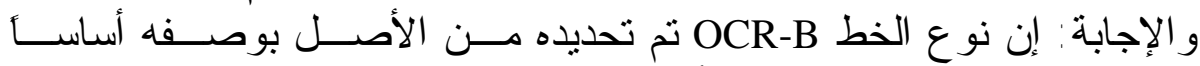

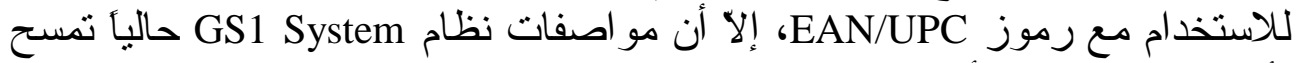
بأي نوع خط طالما أنه و اضح للقر اءة.

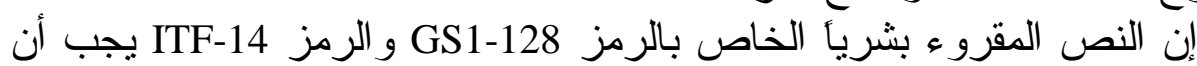

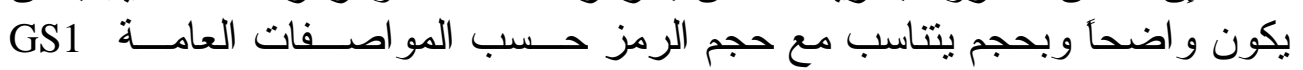
.General Specifications r. هل يفترض أن يكون النص الخاص بالقراعة البشرية أعلــى أم أسـفل رمــز

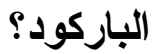

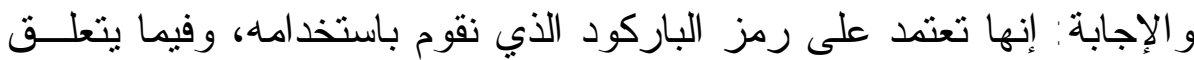

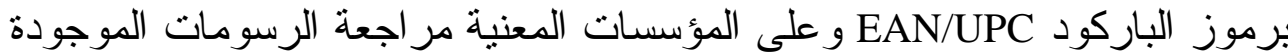

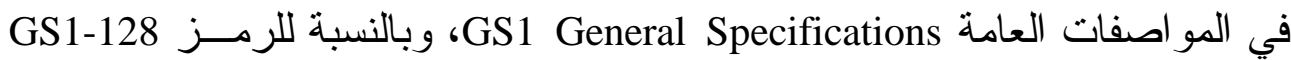
و الرمز ITF-14 فإنه بالإمكان طباعة النص فوق أو تحت الرمز حسب المو اصفات

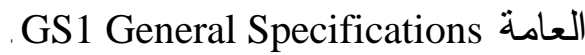
الخطوة ^: تحديد لون الباركود

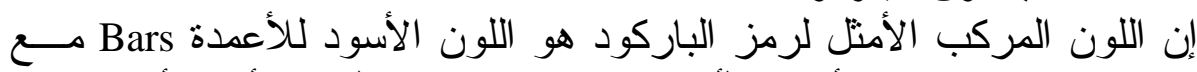

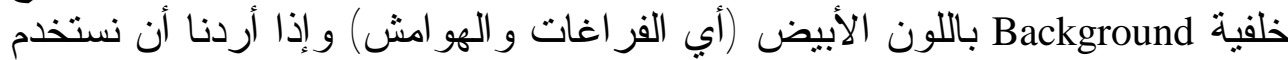

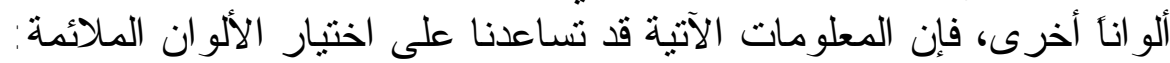

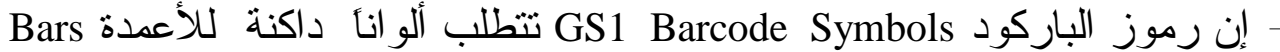
(منل الألوان: الأسود، الأزرق الداكن، البني الداكن الأخضر الداكن الدن)

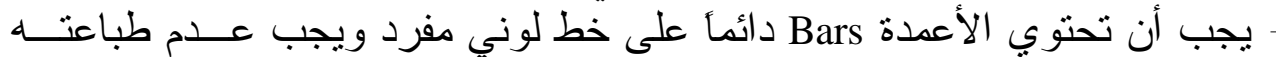
بأدو ات تصوير متعددة.

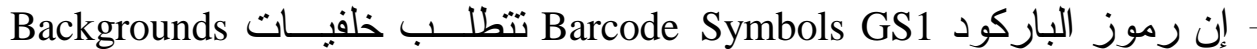

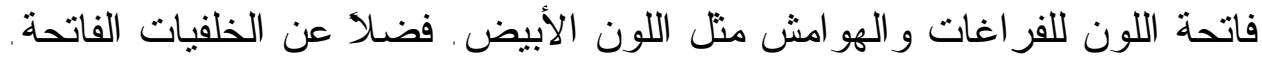

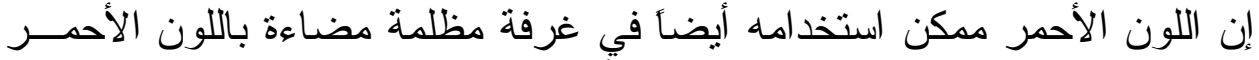

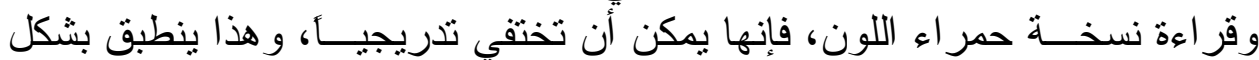

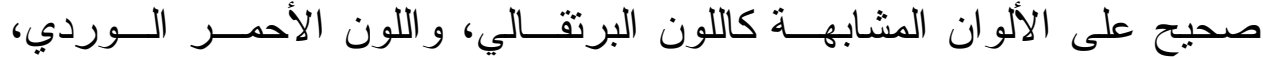

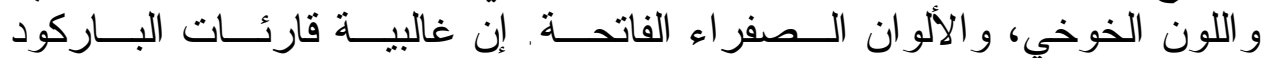

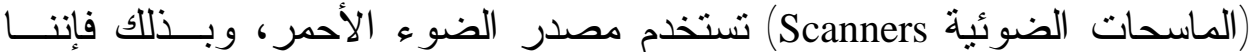

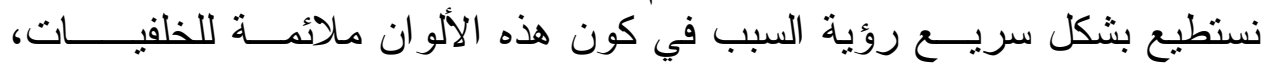
لكن يجب تجنب استخدام هذه رولئ الألوان للأعمدة.

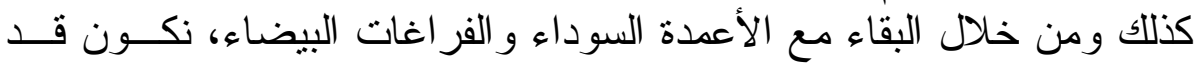

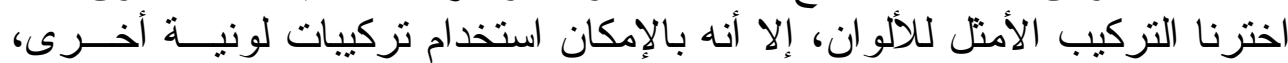




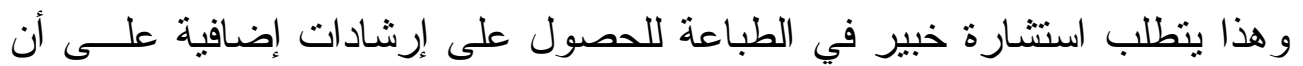

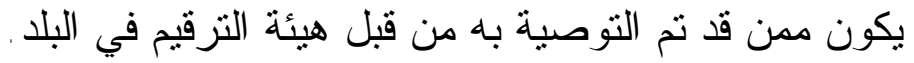

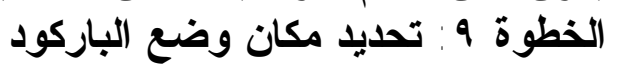

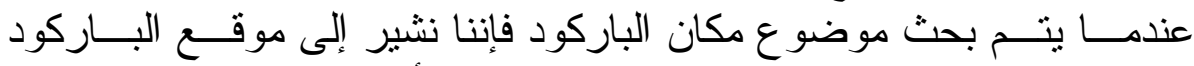

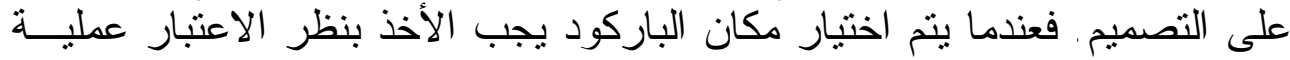

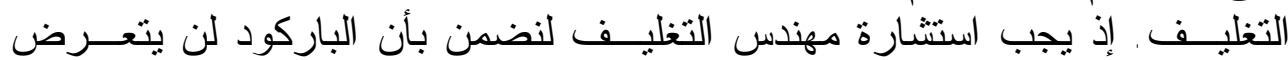

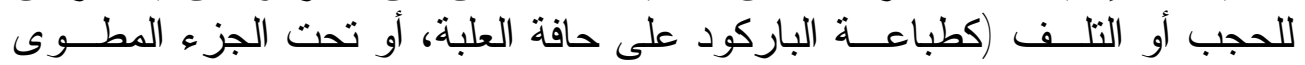

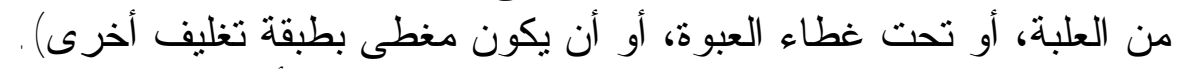

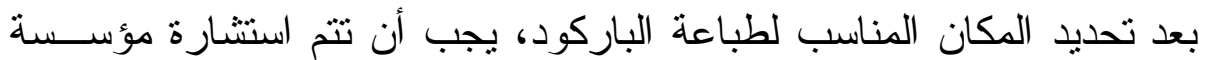

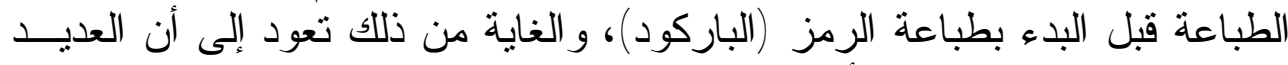

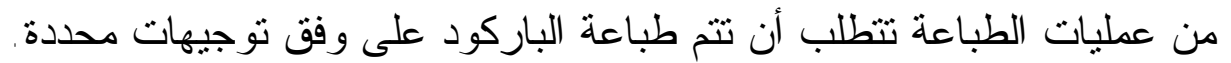
الخطوة · 1 : القيام بيناء خطة جودة الباركود

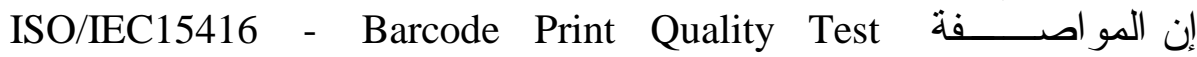
Specification for Linear Symbols

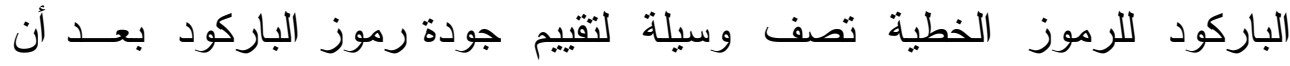

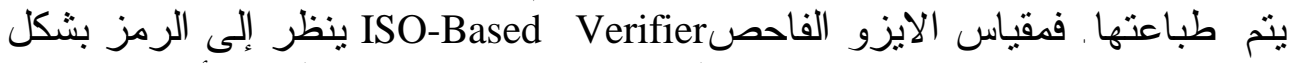

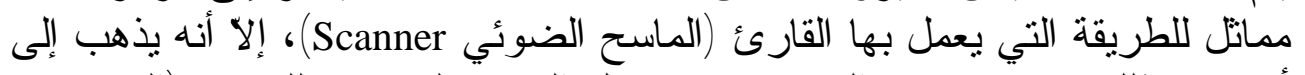

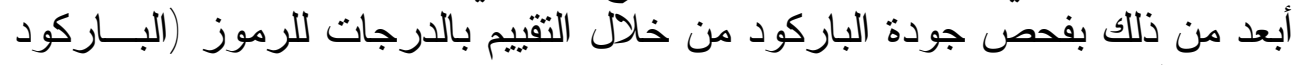

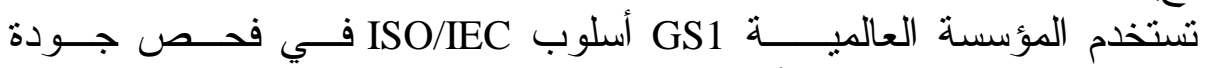

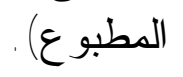

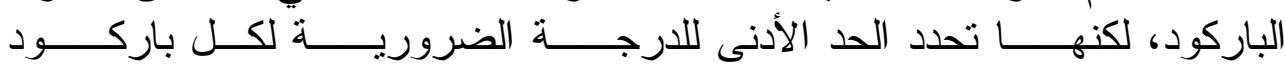
GS1 Barcodes

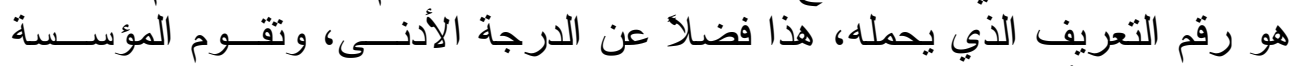

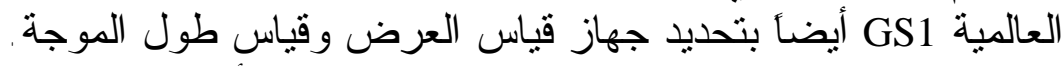

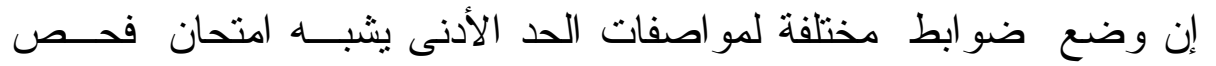

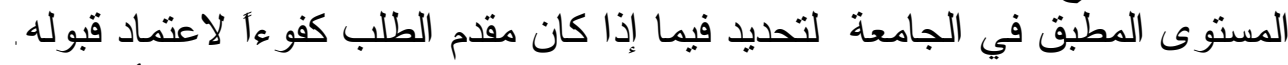

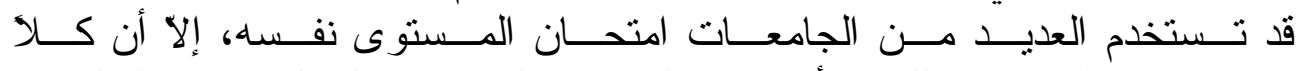
منها يضع الضو ابط للحد الأدنى من الدرجات الضرورية لقبول الفئ مقدمي الطلبات.

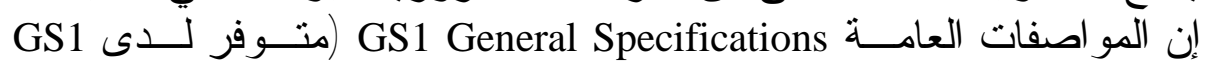

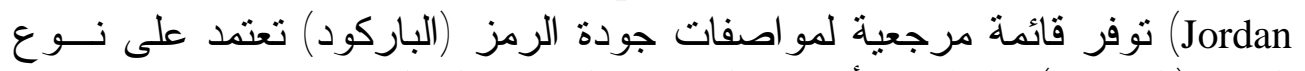

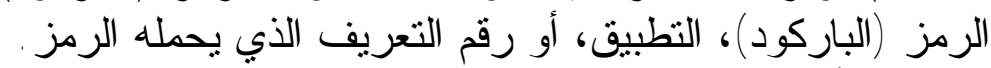

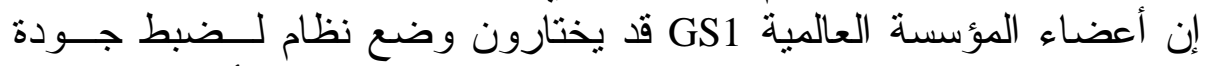

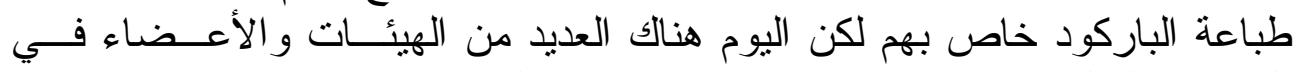

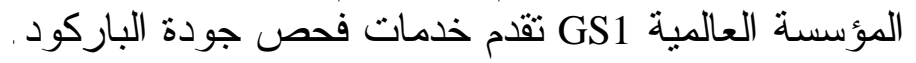


رموز EAN/UPC

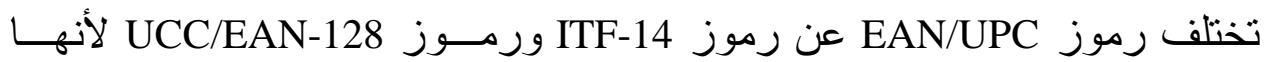

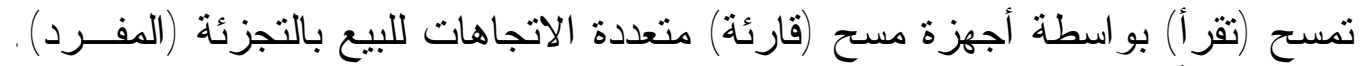

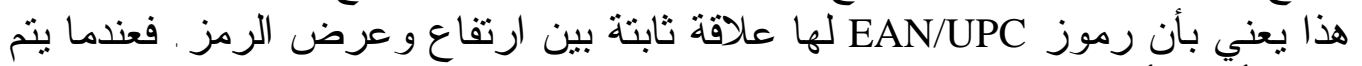

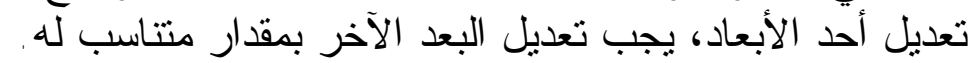

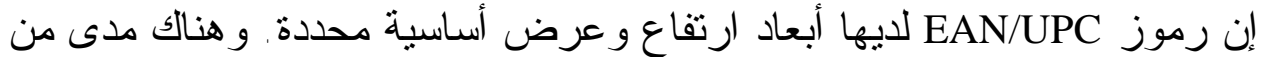

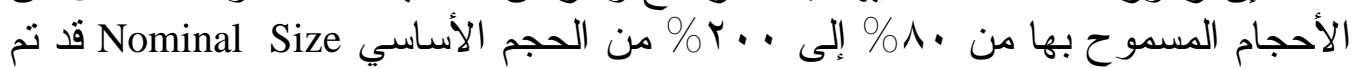

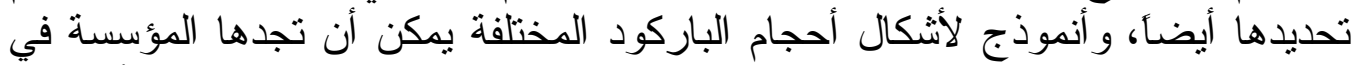

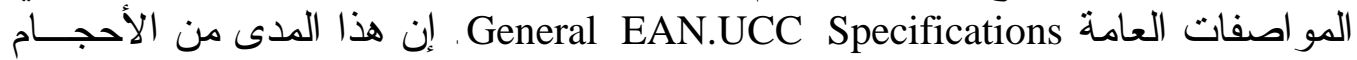

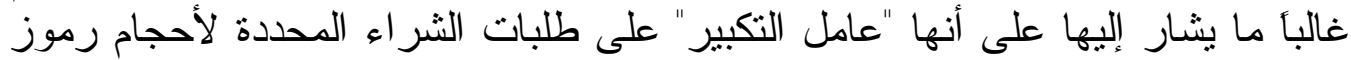
EAN/UPC موضح في الثكل 9.
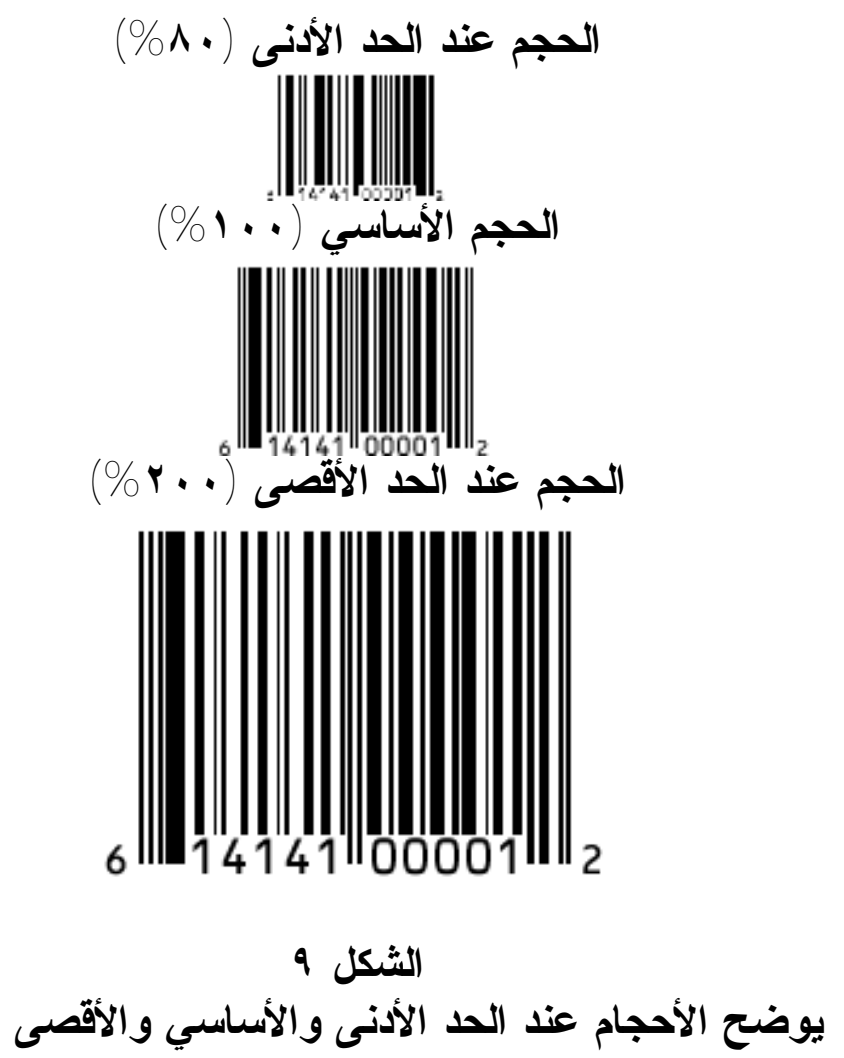


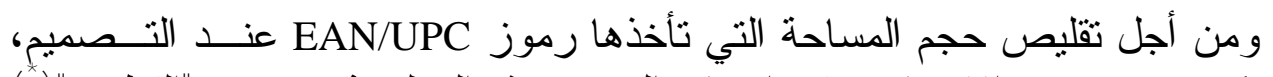

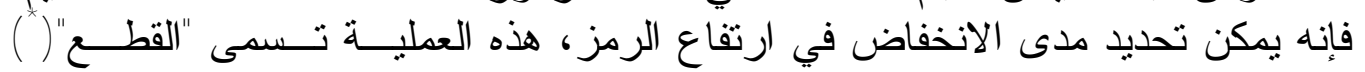

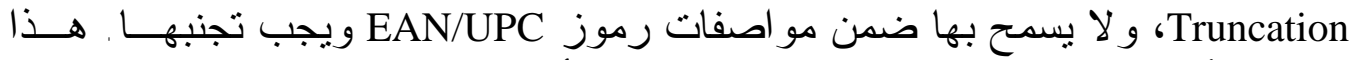

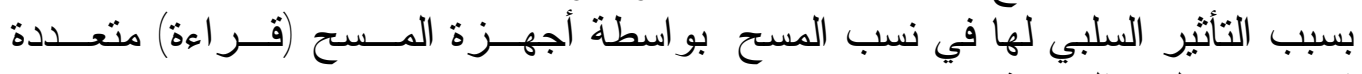
الاتجاهات لبيع التجزئة.

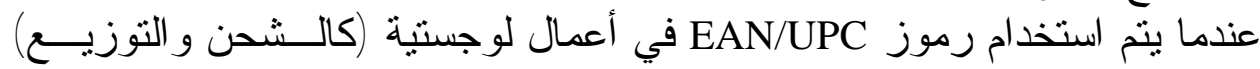

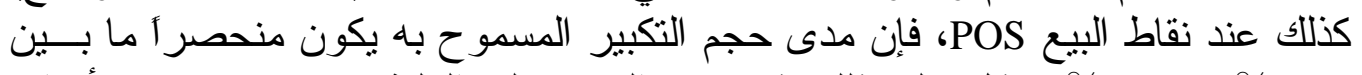

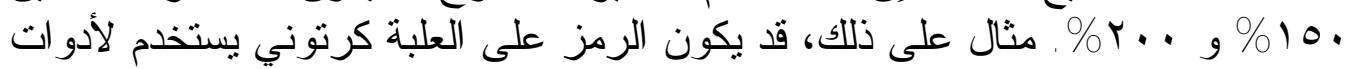

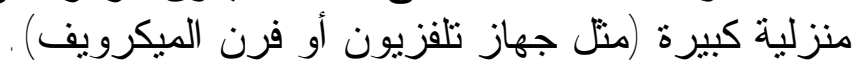

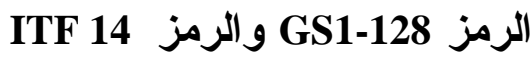

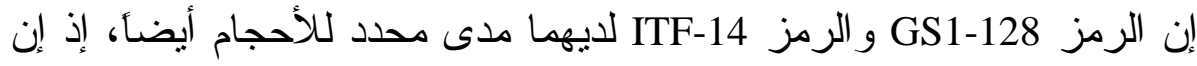

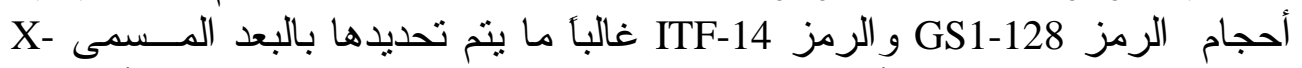

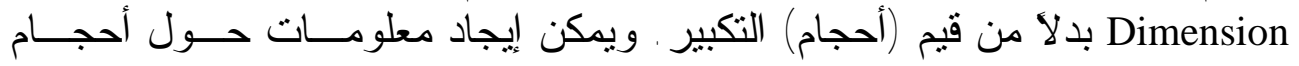
الرمز GS1-128 و الرمز

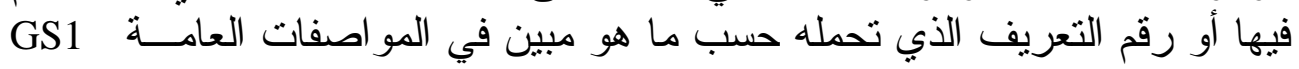

. General Specification

\section{وضع فراغات بين رموز النص؟}

إن رموز EAN/UPC تحدد الفر اغ بين الرسومات، و العديد من المؤســسات

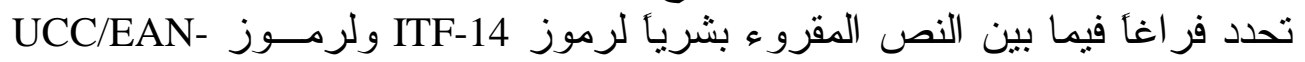

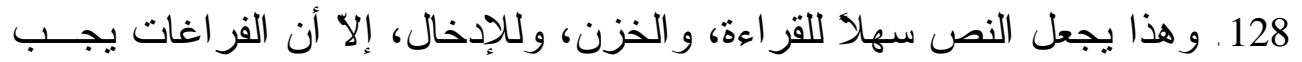

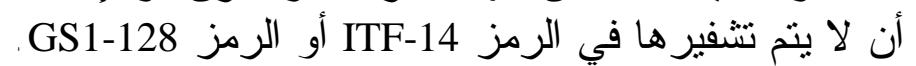

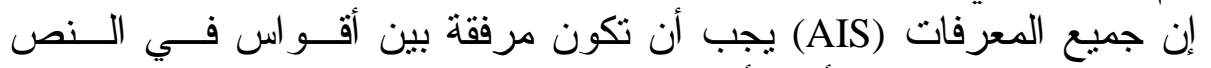

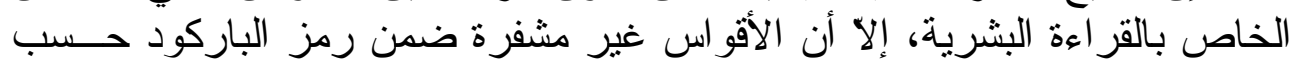
المو اصفات العامة GS1 General Specifications.

\section{اعتبار ات خاصة بعملية الطباعة}

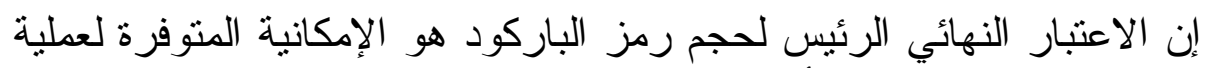

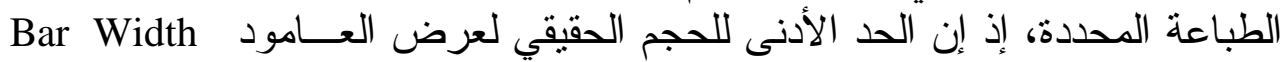
Reduction (BWR)

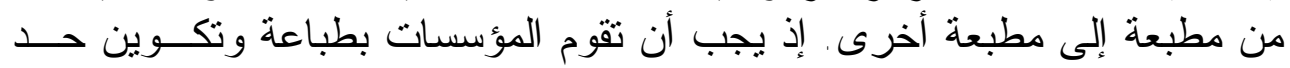

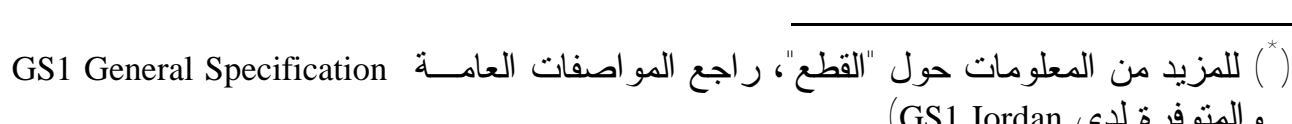




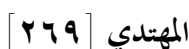

أدنى لحجم الرمز لعرض العامود BWR للتوصل إلى نتائج مقبولة وجودة متكررة

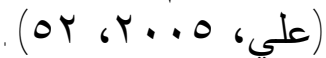

\section{مزايا ترقيم المنتجات المصنعة}

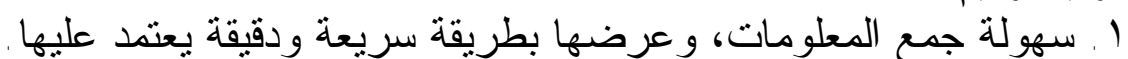

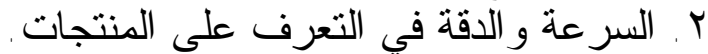
r. أتمتة عمليات بيع المنتجات في نقاط البيع Point of Sale لدى المخازن التجارية

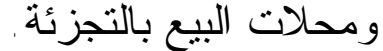

ع ـ ضبط حركة المخزون، وتقئليل الهادر الناتج عن انتهاء صلاحية المنتجات. ه. يعد ترقيم المنتج في شكل بار كود وسيلة بسيطة وغير مكير مكلفة للتمكين من تخزين وجلب البيانات أنوماتيكياً.

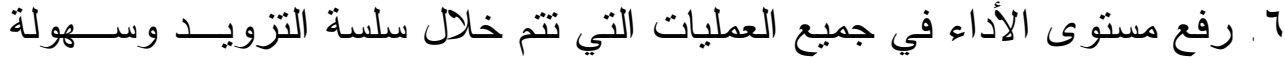

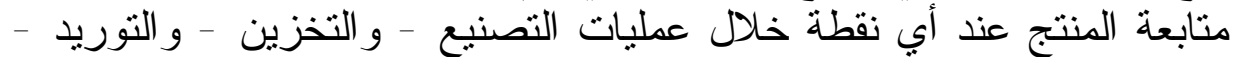

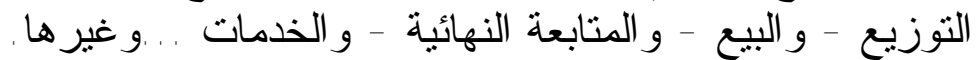

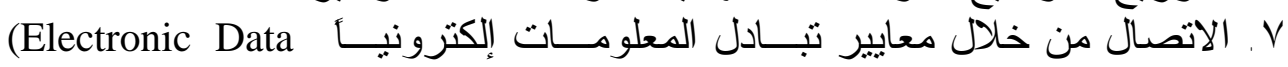
. Interchange EDI) ^ـ رفع كفاءة خدمة الزبائن بالإسر اع في عمليات البيع و الدفع من خــلال تـــوفير

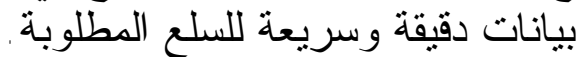

9 ـ نرقيم المنتجات وفقأ لنظام ترقيم عالمي يعد لغة موحدة للجية للجميع، وبطاقة تعريف ل اللمصنع و المنتج محلياً ودولياً.

• 1 ـ رفع القدرة التتافسية للمصنع سو اء في الأسواق المات المحلية أو العالمية من خلال

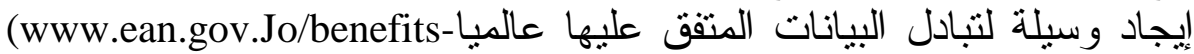
. a.htm)

تم اختيار معرض البيع المباشر للكتب و المستلزمات الدر اسية في مديرية دار

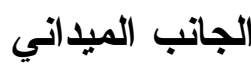

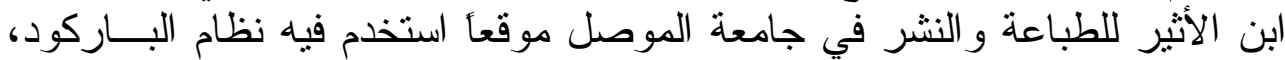

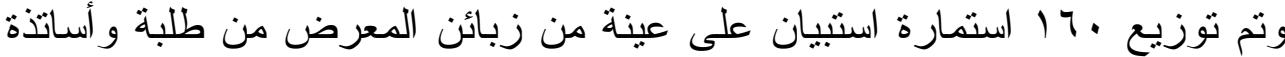

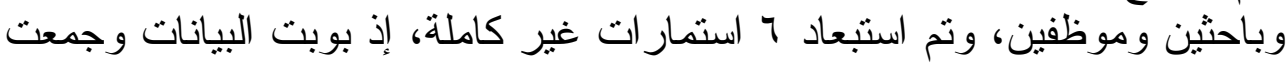

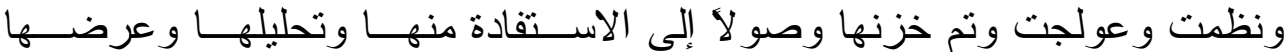

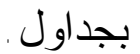

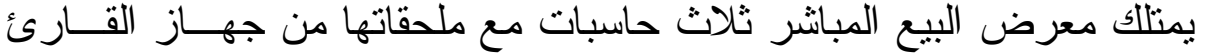

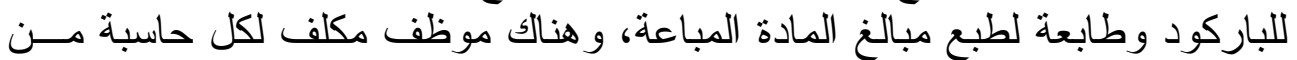

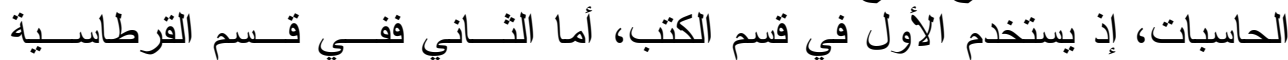

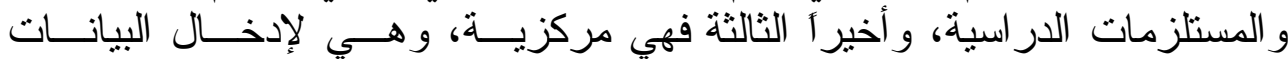

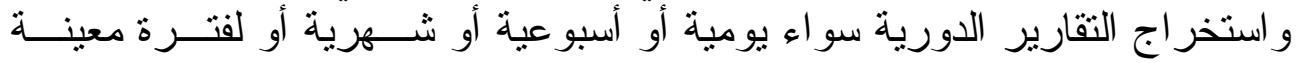




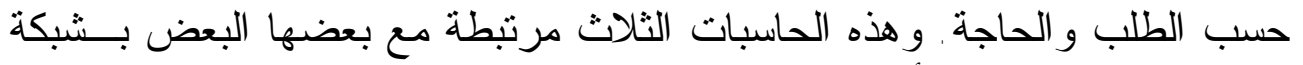

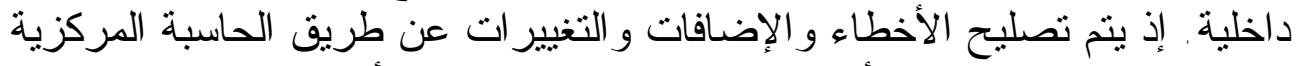

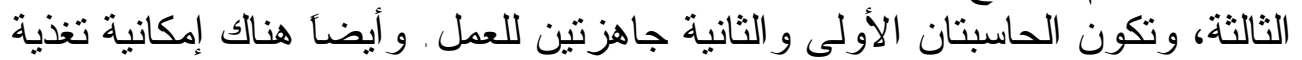

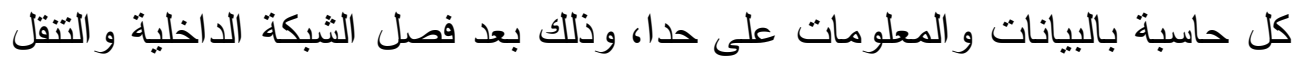

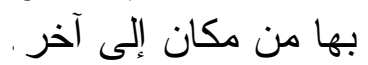

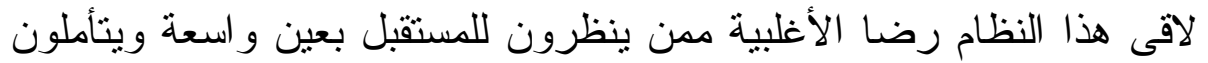

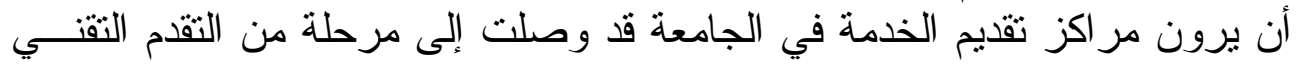

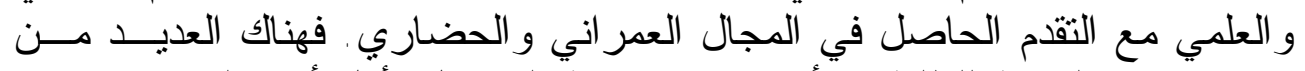

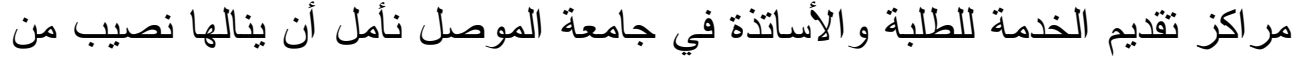

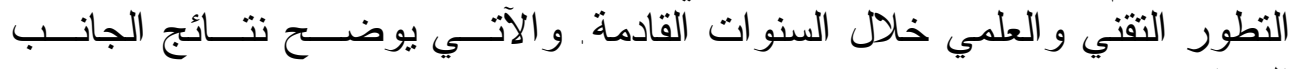

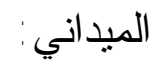

أولاً - وصف عينة البحث

\begin{tabular}{|c|c|c|c|c|c|}
\hline \multicolumn{6}{|c|}{ 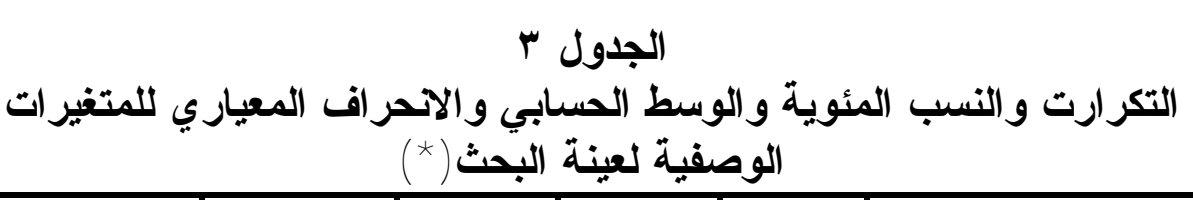 } \\
\hline المجموع & الالحيرافي & الحسابي & $\%$ & التكرار & العبارة \\
\hline \multirow{3}{*}{$10 \leqslant$} & \multirow{3}{*}{$\cdot, \leqslant 9$} & & & & الجنس \\
\hline & & \multirow{2}{*}{1,00} & $\varepsilon \varepsilon, \Lambda$ & 79 & ذكر \\
\hline & & & $00, r$ & 10 & أنثى \\
\hline \multirow{6}{*}{$10 \leqslant$} & \multirow{6}{*}{$1, r \varepsilon$} & & & & العمر \\
\hline & & \multirow{5}{*}{ T,Tr } & $r \cdot, 1$ & $r$ & أقل من Yo سنة \\
\hline & & & $r \mu, \Lambda$ & Or & $r_{.-r_{0}}$ \\
\hline & & & $1 \leqslant, 9$ & $r \mu$ & 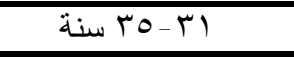 \\
\hline & & & 17,9 & rY & با -..ع سنة \\
\hline & & & $T \varepsilon, r$ & Tr & إ - فما فوق \\
\hline \multirow{4}{*}{$10 \varepsilon$} & \multirow{4}{*}{$\cdot, 01$} & & & & الحالة الاجتماعية \\
\hline & & \multirow{3}{*}{1,09} & 09,1 & 91 & متزوج \\
\hline & & & $r 0, V$ & 00 & أعزب \\
\hline & & & $0, r$ & $\Lambda$ & مطلق \\
\hline \multirow{6}{*}{$10 \varepsilon$} & \multirow{6}{*}{$1, r 4$} & & & & التحصيل الدراسي \\
\hline & & \multirow{5}{*}{$r, r$} & $V, r$ & 11 & ما دون البكالوريوس \\
\hline & & & $\varepsilon \cdot, 9$ & 74 & بكالوريوس \\
\hline & & & $V, \Lambda$ & IT & دبلوم \\
\hline & & & $r q, r$ & $\leqslant 0$ & ماجستير \\
\hline & & & $1 \leqslant, 9$ & Tr & دكتور اه \\
\hline $10 \xi$ & & & & & المهنة \\
\hline
\end{tabular}


المهندي [ [ ]

\begin{tabular}{|c|c|c|c|c|c|}
\hline المجموع & الالمعيار افي & الحسابي & $\%$ & التكرار & العبارة \\
\hline & \multirow{4}{*}{$1, \cdot \varepsilon$} & \multirow{4}{*}{ r, rV } & $r \varepsilon$ & rV & موظف \\
\hline & & & 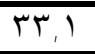 & 01 & طالب در اسات أولية \\
\hline & & & $r \varepsilon, V$ & rᄉ & طالب در اسات عليا \\
\hline & & & $\overline{1 \wedge, r}$ & rᄉ & ت تلريسي \\
\hline
\end{tabular}

ثانياً - تحليل متغيرات البحث بأسلوب العرض والتوحيد

\begin{tabular}{|c|c|c|c|c|c|c|c|}
\hline \multicolumn{8}{|c|}{ الجدول ع } \\
\hline المجموع & لا لاما & لا اتفق & محايد & اتفق & ت اتفقا & المتغير ات & \\
\hline $10 \leqslant$ & - & - & $\varepsilon$ & $7 \wedge$ & NT & 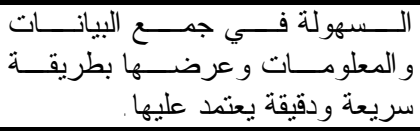 & .1 \\
\hline $10 \leqslant$ & - & - & - & $r \varepsilon$ & $1 \pi$. & السنترعات . الدقة في التعـرف علــى &.$r$ \\
\hline $10 \leqslant$ & & - & 9 & 9 . & 00 & 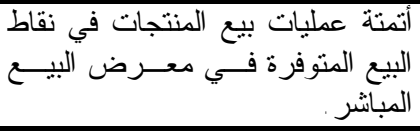 &.$r$ \\
\hline $10 \leqslant$ & - & $\varepsilon$ & $\wedge$ & $\varepsilon r$ & $1 \ldots$ & ضاتبط حركة المخزون، وتقليل الهناء صنات المنات &.$\varepsilon$ \\
\hline $10 \leqslant$ & - & Ir & IV & $\wedge$ & $\varepsilon \varepsilon$ & بعد ترميز المنتجات وترقيمها بشكل & .0 \\
\hline $10 \leqslant$ & & - & - & vo & $\vee q$ & 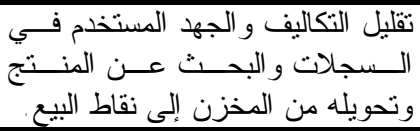 & .7 \\
\hline $10 \leqslant$ & & - & $r$ & $\varepsilon \wedge$ & $1 . r$ & 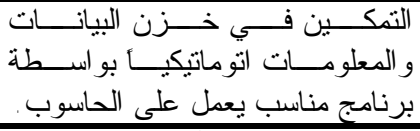 &.$V$ \\
\hline $10 \leqslant$ & & & 0 & or & 97 & 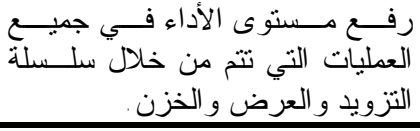 &.$\wedge$ \\
\hline $10 \leqslant$ & & - & r & $\varepsilon V$ & 1.0 & 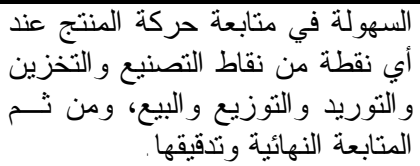 & .9 \\
\hline $10 \leqslant$ & & - & - & rq & Iro & 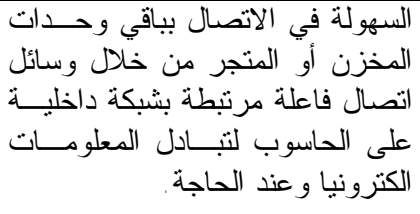 & .1 . \\
\hline
\end{tabular}




\begin{tabular}{|c|c|c|c|c|c|c|c|}
\hline المجموع & لا اتفق & لا اتفق & محايد & اتفق & تمامقا & المتغيرات & \\
\hline $10 \varepsilon$ & - & - & - & 19 & 1ro & 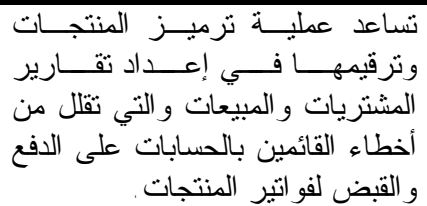 & .11 \\
\hline $10 \leqslant$ & - & - & - & Tr & $|K|$ & 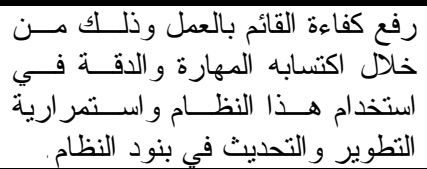 & $.1 Y$ \\
\hline $10 \varepsilon$ & - & 11 & Tr & $\varepsilon r$ & $\mathrm{VA}$ & 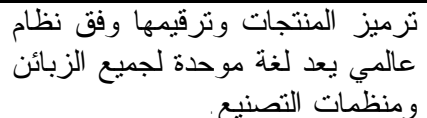 & $.1 \pi$ \\
\hline $10 \xi$ & - & $\wedge$ & 19 & rT & 90 & 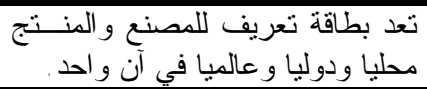 & $.1 \varepsilon$ \\
\hline $10 \leqslant$ & - & - & - & rT & IKr & 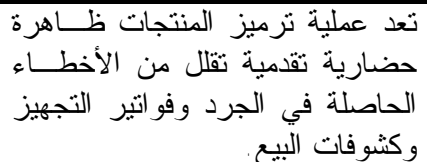 & .10 \\
\hline $10 \xi$ & - & - & - & 00 & 99 & 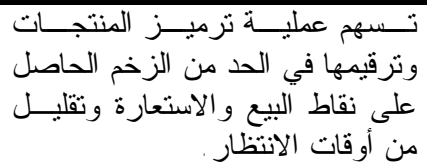 & .17 \\
\hline
\end{tabular}

\begin{tabular}{|c|c|c|c|c|c|c|c|}
\hline \multicolumn{8}{|c|}{ التقويم النهائي لتوجهات زبائن معرض البيع المباشر(*) } \\
\hline المجموع & لالا اتفق & التق & محايد & اتفق & تماما & المتغيرات & ت \\
\hline TrT & - & - & صفر & 71 & $17 \varepsilon$ & وعليها. & $T$ \\
\hline$r \wedge \varepsilon$ & - & - & صفر & $r \varepsilon$ & r. & المنتجاتة و الدقــة فــي التـــرف علـى & $\bar{T}$ \\
\hline$r .$. & - & - & صفر & 9. & 11. & 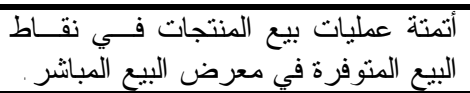 & $r$ \\
\hline rHA & - & $\varepsilon-$ & صفر & $\leqslant r$ & $r .$. & 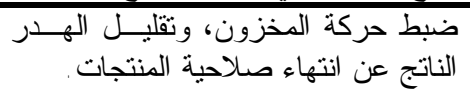 & $\varepsilon$ \\
\hline $10 \mathrm{~V}$ & - & IY. & صفر & 1) & $\Lambda \wedge$ & 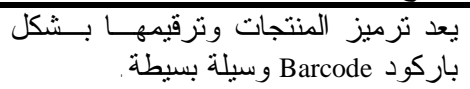 & 0 \\
\hline TTI & - & - & صفر & vo & 101 & 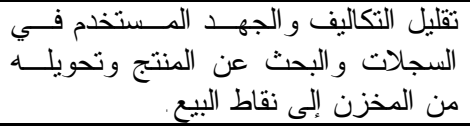 & 7 \\
\hline
\end{tabular}




\section{المهتدي [rVYr}

\begin{tabular}{|c|c|c|c|c|c|c|c|}
\hline المجموع & لا تاما اتفق & اتلق & محايد & اتفق & تمامقا & المتغيرات & ت \\
\hline Yos & - & - & صفر & $\leqslant \wedge$ & $r \cdot T$ & 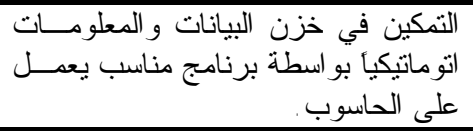 & $\bar{V}$ \\
\hline$r \leq \varepsilon$ & - & - & صفر & or & 194 & 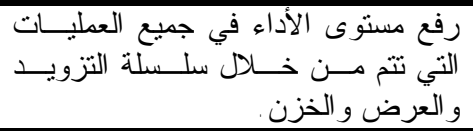 & $\bar{\Lambda}$ \\
\hline rov & & - & صفر & $\varepsilon V$ & r). & 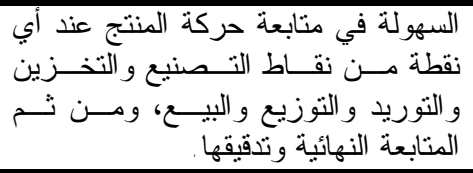 & 9 \\
\hline rVq & & - & صفر & rq & ro. & 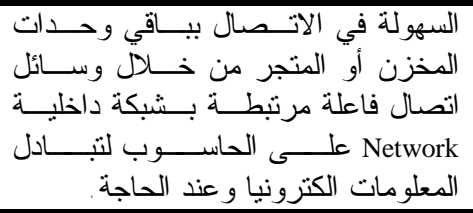 & 1. \\
\hline$r \wedge q$ & & 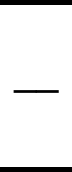 & صفر & 19 & $r v$. & 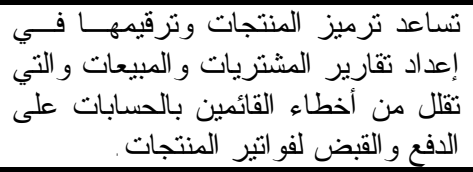 & 11 \\
\hline r^o & & $\ldots$ & صفر & זr & $r \leqslant r$ & 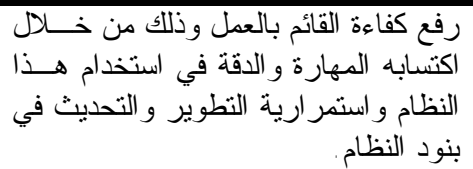 & $T$ \\
\hline INV & & $11-$ & صفر & $\varepsilon r$ & 107 & 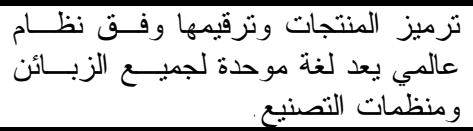 & $T$ \\
\hline YIE & 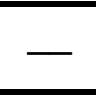 & $\Lambda-$ & صفر & r & 19. & ودوليا و عالمبا في آن و احدن و والمنتج محليا & $1 \varepsilon$ \\
\hline TVT & & - & صفر & rt & $r \leqslant \varepsilon$ & 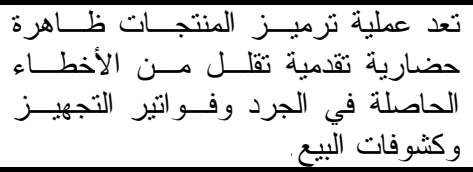 & 10 \\
\hline ror & & - & صفر & 00 & 191 & 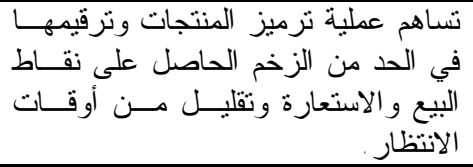 & 17 \\
\hline
\end{tabular}

(*) (العداد الباحث

وبعد تقييم توجهات زبائن معرض البيع المباشر ، نم التوصل إلى بيان الأهمية

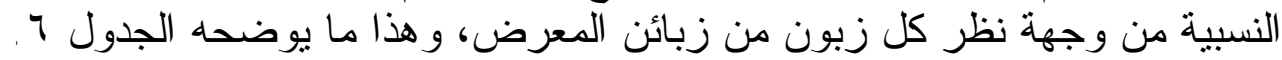


الجدول

بيان الأهمية النسبية والوسط الحسابي والآحراف المعياري من وجهة نظر زبائن

معرض البيع المباشر(*)

\begin{tabular}{|c|c|c|c|c|}
\hline الالتحر افياري & الوسطب & الأهمية & المتغير ات & 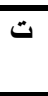 \\
\hline$\cdot$ • ז & $\varepsilon, \wedge \vee \neg \uparrow$ & r^৭ & 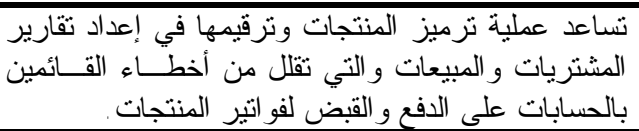 & 11 \\
\hline$\cdot, \leqslant 117$ & $\varepsilon, \wedge \vee \circ \vee$ & r^o & 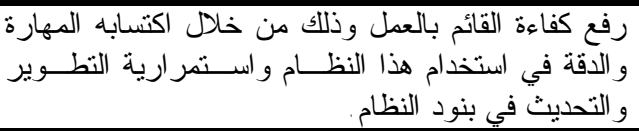 & it \\
\hline$\cdot$, rTr人 & $\varepsilon, \wedge \varepsilon \varepsilon Y$ & $r \wedge \varepsilon$ & السر عة و الدقة في التعرف على المنتجات. & r \\
\hline$\cdot$, rqYr & $\varepsilon, \wedge 11 \mathrm{~V}$ & rvq & 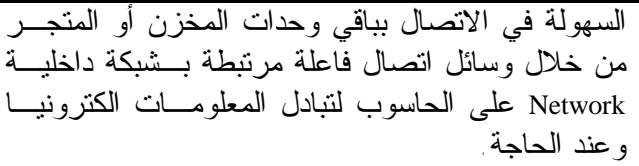 & 1 . \\
\hline$\cdot, \varepsilon \cdot \vee \cdot$ & $\varepsilon, V q T r$ & rVT & 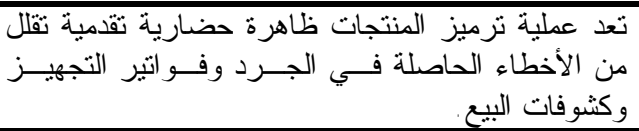 & 10 \\
\hline$\cdot, \leqslant 99$. & $\varepsilon, 77 \wedge \Lambda$ & rov & 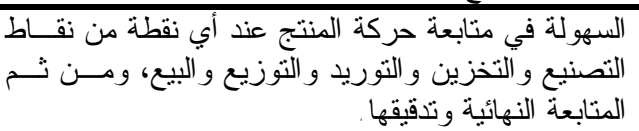 & 9 \\
\hline., 011 & $\varepsilon, 7 \leqslant 9 \leqslant$ & ros & التمكين في خزن بعل البيانات و المعلومات اتوماتيكياً بو اسطة & $\mathrm{V}$ \\
\hline$\cdot, \leqslant \Lambda \cdot \vee$ & $\leqslant, 7 \leq r q$ & ror & 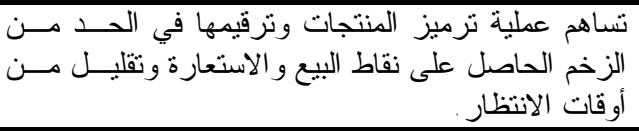 & 17 \\
\hline., $071 \mathrm{r}$ & $\varepsilon, 0 \wedge \varepsilon \varepsilon$ & $r \leq \varepsilon$ & رفلع مستوى التزويد والعرض في جميع العطليات التي تتم من خلال & $\Lambda$ \\
\hline$\cdot, \vee \backslash \leq \Lambda$ & $\leqslant, 0 \leqslant 00$ & r隹 & صناحية حركة المنتجات. & $\varepsilon$ \\
\hline., $0.1 \leq$ & $\varepsilon, 01 \pi$. & מזr & 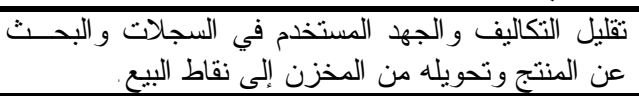 & 7 \\
\hline., $001 \mathrm{r}$ & $\varepsilon, 0.70$ & Trt & سريعة ودقيقة جيتمد البيانات و المعلومات وعرضها بطريقة & 1 \\
\hline$\cdot, \wedge 90 \mathrm{r}$ & $\Sigma, \Gamma \wedge q 7$ & Y) & في آن و احدة تعريف للمصنع و المنتج محليا ودوليا و عالميا & $1 \varepsilon$ \\
\hline., $0 \vee M 1$ & $\varepsilon, Y q \wedge \vee$ & r.. & أتمتنة عمليات بيع المنتجات في نقاط البيع المتوفرة فــي & $r$ \\
\hline$\cdot, 9 \leq 9 \leq$ & $\varepsilon, r \mid \leq r$ & $1 \wedge \mathrm{V}$ & 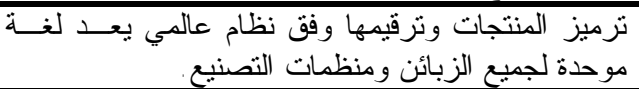 & $\pi$ \\
\hline$\cdot, \lambda \leq r \wedge$ & $5, .190$ & $10 \mathrm{~V}$ & يعد ترميز المنتجات وترقيمها بشكل بــاركود & 0 \\
\hline
\end{tabular}

(*) من إعداد الباحثة. 


\section{[ المهتدي [rvo}

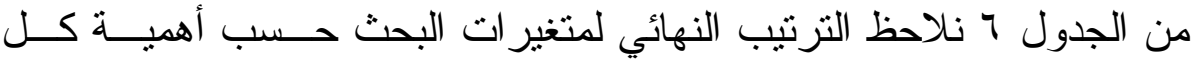

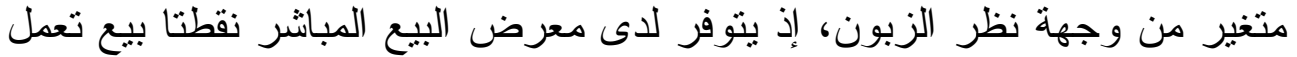

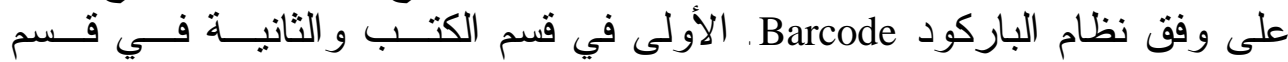

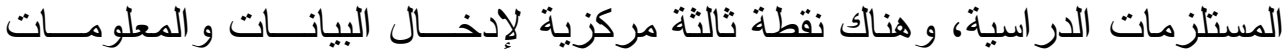

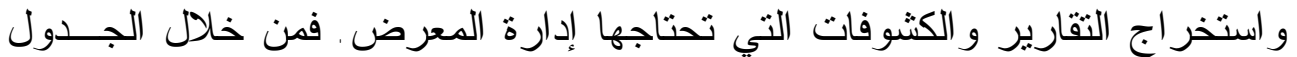

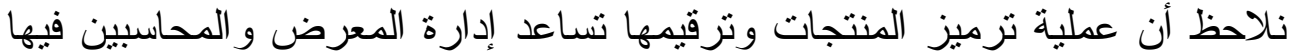

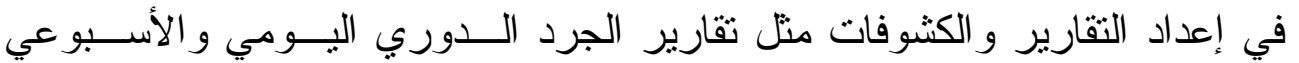

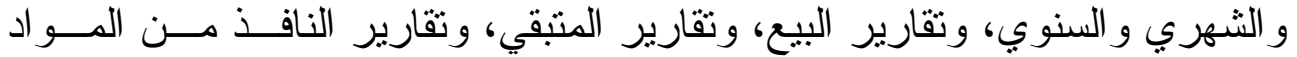

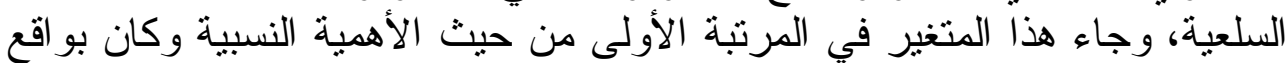

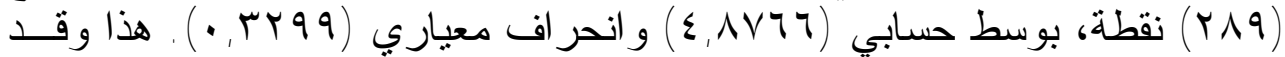

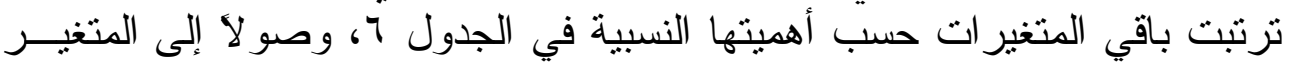

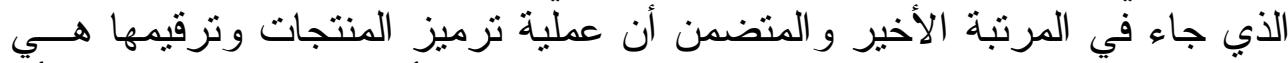

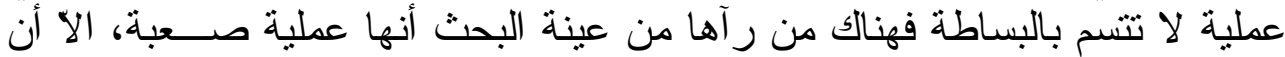

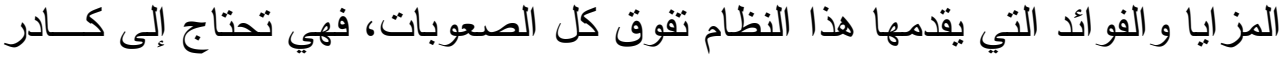

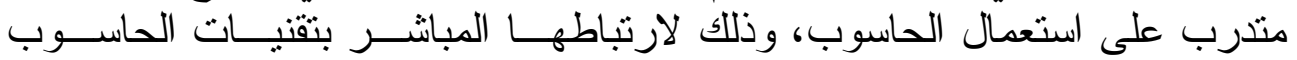

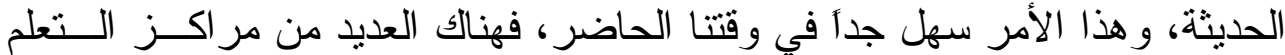

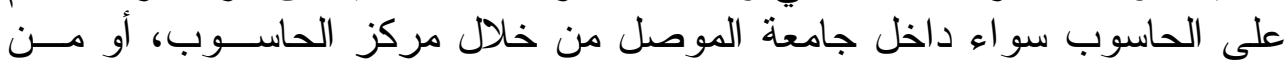

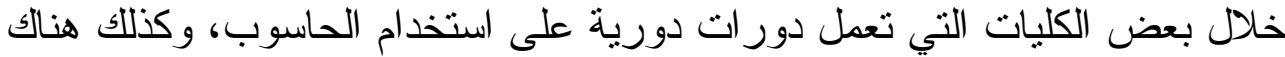

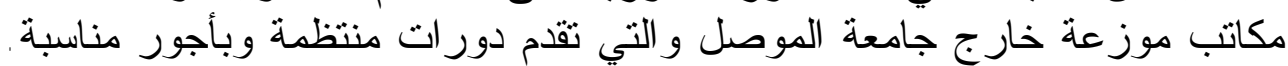

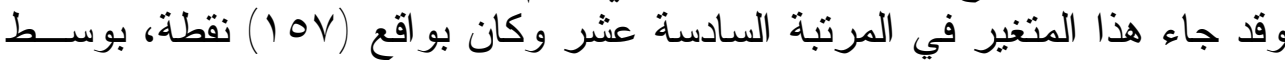

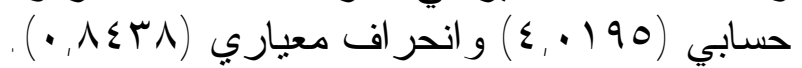

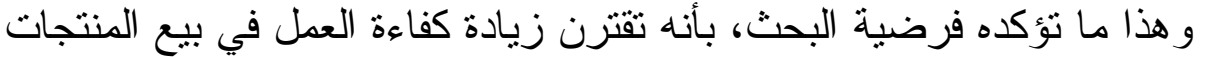
باستخدام الرمز السلعي (Barcode).

الاستتناجات و التوصيات

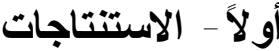

خلص البحث إلى عدد من الاستتناجات التي كانت من أولويــــة عهــل إدارة

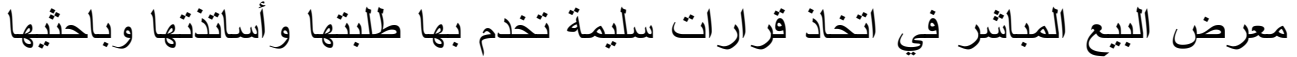

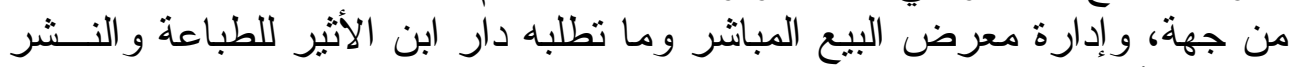

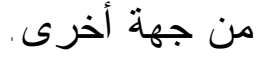

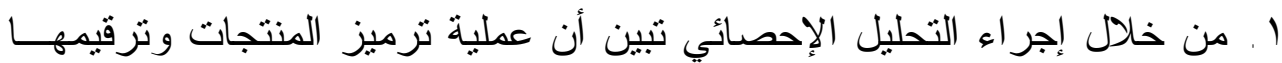

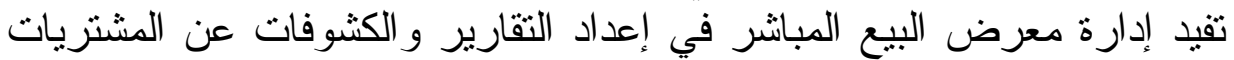

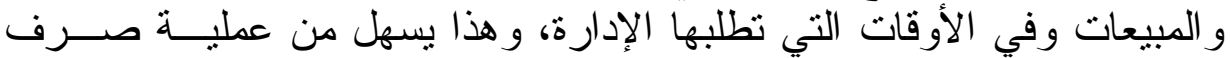

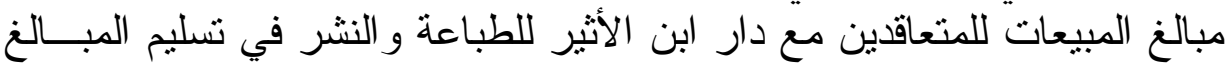


إليهم وحسب العقد المبرم بين الطرفين (الـــار - الجهـــة المـزودة للمنتجــات

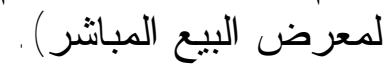

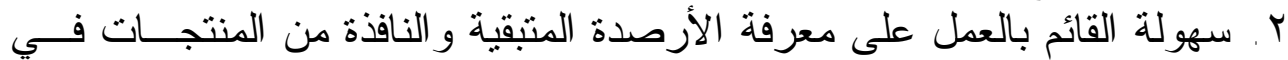

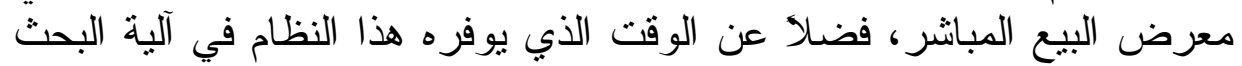

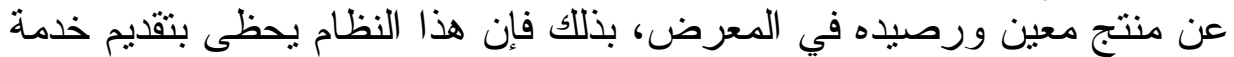

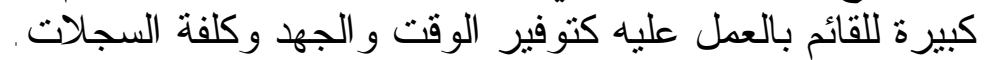

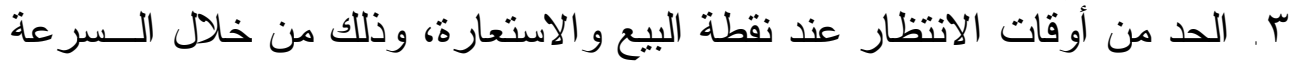

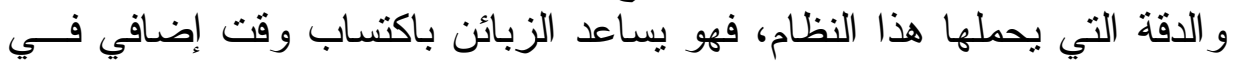

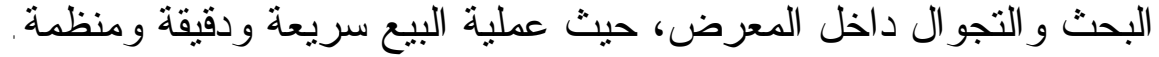

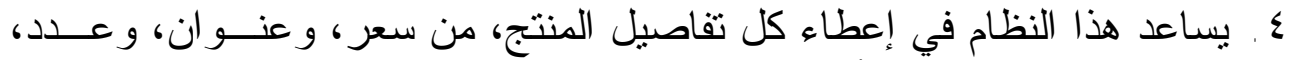

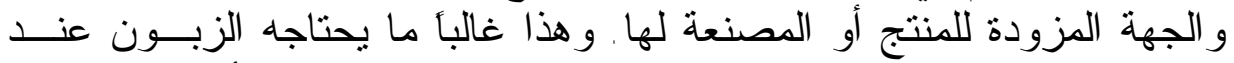

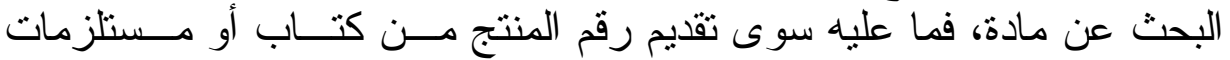
در اسية.

\section{ثانياً - التوصيات}

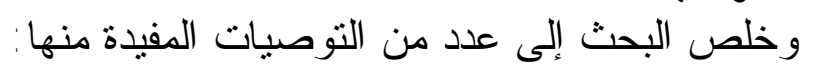

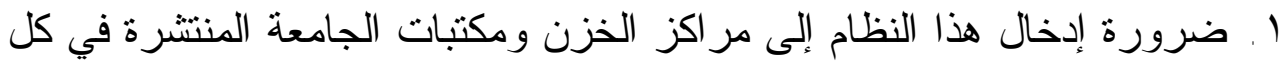

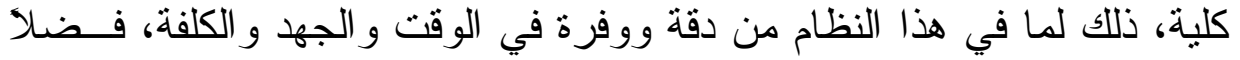

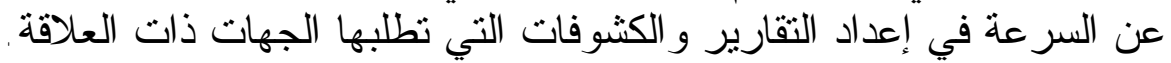

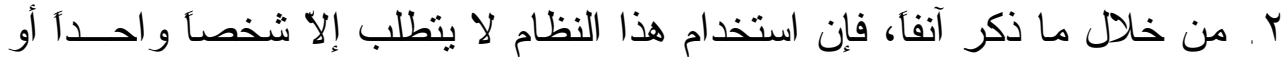

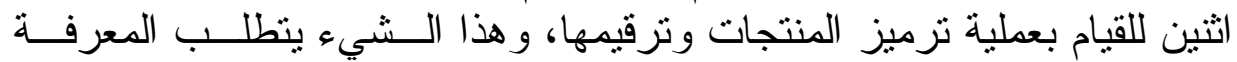

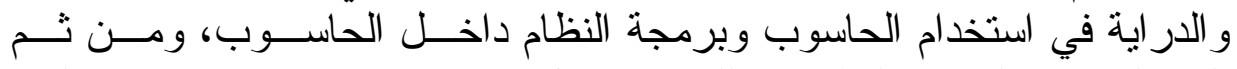

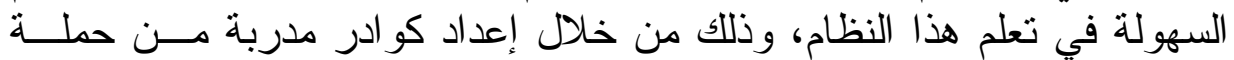

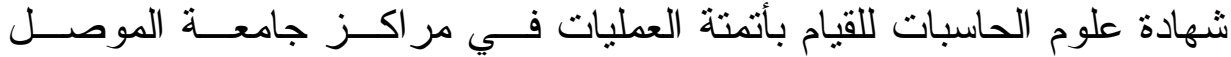

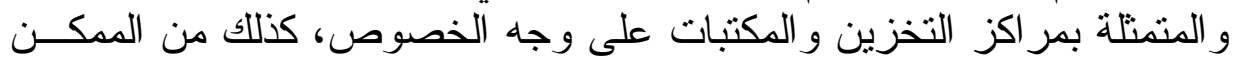

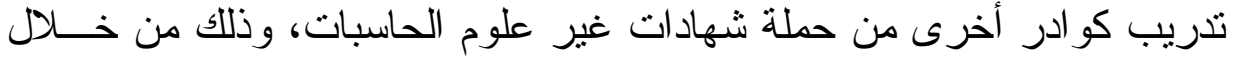
إقامة دور ات تخصصية في مجال الحاسوب ونظام ترقيم المنتجات وترميز ها.

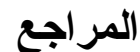 \\ أولاً - المر اجع باللغة العربية}

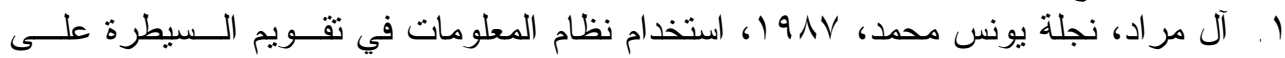

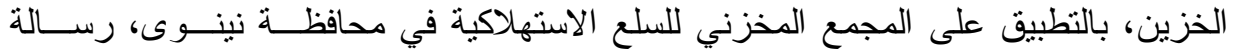

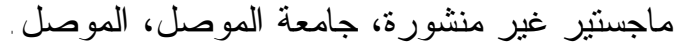

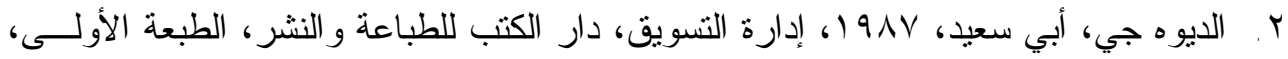




\section{المهندي [rvv}

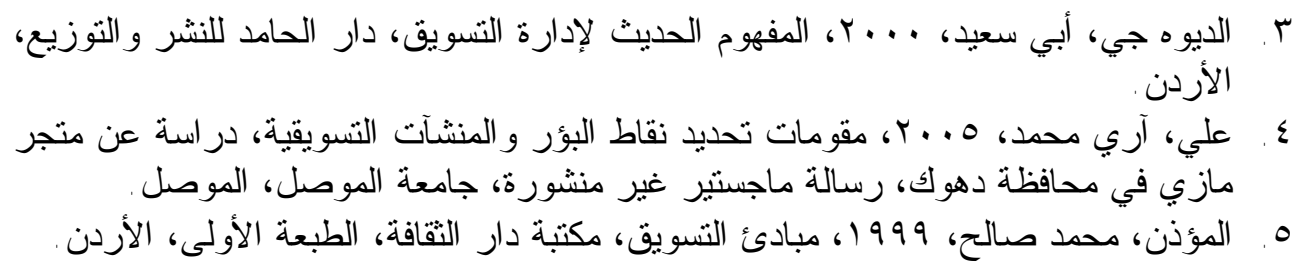

\section{ثانياً - المر اجع باللغة الأجنبية}

1.Brian, Griffiths, 2004, Manufacturing Information and Data System: Analysis, Design and Practice, Cogan Page Inc., USA.

2. Dibb, Sally, Simkin, Lyndon, and Ferrell, O.C., 1994, Marketing: Concept and Strategies, Houghton Mifflin Company, London.

3. Riasecki,, David J., 2003, Inventory Accuracy : People, Processes, Technology, Ops Publishing, London, UK.

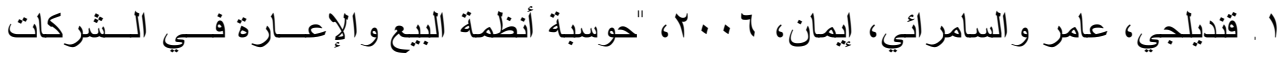

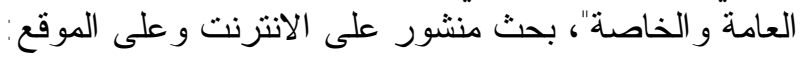

www.google.com/search/barcodes.html

2. www.invetors.about.com/mbiopage.html

3. www.invetors/MaryBellis.page.html

4. www.evrytype.com/standards/og/ogmhare

5. www.electronics.howstuffworks.com/UPC.html

6. www.ean.jedco.gov.jo/barcode-steps-a.htm6.

7. www.ean.Jedco.gov.Jo/barcode-quality-a.htm

8.www. Jordan Numbering Association.com, 2006

9.www.ean.gov.Jo/benefits-a.htm 